\title{
Is There a Glutathione Centered Redox Dysregulation Subtype of Schizophrenia?
}

\section{Lena Palaniyappan ${ }^{* 1,2,3,4}$ Min Tae M. Park ${ }^{1}$, Peter Jeon ${ }^{2,3,4}$, Roberto Limongi ${ }^{3}$, Kun Yang ${ }^{5}$, Akira Sawa ${ }^{5,6,7,8}$, Jean Théberge ${ }^{1,2,4}$}

1. * Department of Psychiatry, Schulich School of Medicine and Dentistry, Western University, London, Canada. lpalaniy@uwo.ca

2. Department of Medical Biophysics, Western University, London Canada

3. Robarts Research Institute, Western University, London, Canada.

4. Lawson Health Research Institute, London, Canada.

5. Department of Psychiatry and Behavioral Sciences, Johns Hopkins University School of Medicine, Baltimore, MD, USA

6. Department of Biomedical Engineering, Johns Hopkins University School of Medicine, Baltimore, MD, USA

7. Department of Neuroscience, Johns Hopkins University School of Medicine, Baltimore, MD, USA

8. Johns Hopkins Bloomberg School of Public Health, Baltimore, MD, USA

\begin{abstract}
Schizophrenia continues to be an illness with poor outcome. Most mechanistic changes occur many years before the first episode of schizophrenia; these are not reversible after the illness onset. A developmental mechanism that is still modifiable in adult life may center on intracortical glutathione (GSH). A large body of pre-clinical data has suggested the possibility of notable GSHdeficit in a subgroup of patients with schizophrenia. Nevertheless, studies of intracortical GSH are not conclusive in this regard. In this review, we highlight the recent ultra-high field magnetic resonance spectroscopic studies linking GSH to critical outcome measures across various stages of schizophrenia. We discuss the methodological steps required to conclusively establish or refute the persistence of GSH-deficit subtype and clarify the role of the central antioxidant system in disrupting the brain structure and connectivity in the early stages of schizophrenia. We propose in-vivo GSH quantification for patient selection in forthcoming antioxidant trials in psychosis. This review offers directions for a promising non-dopaminergic early intervention approach in schizophrenia.
\end{abstract}

Keywords: glutathione, glutamate, psychosis, schizophrenia, redox, antioxidant, oxidative stress, myelin, spectroscopy

\section{Introduction}

Schizophrenia is one of the most devastating of adolescent onset illnesses. Despite the advances in pharmacological, psychological and social aspects of care in the last 50 years, only a small sub-group achieves combined clinical and functional recovery $(\sim 13 \%)[1,2]$. Over several decades, barely any improvement has occurred in life expectancy and the years of potential life lost[3]. All of the currently available antipsychotics focus on dopamine, but the symptom relief they provide does not translate to functional recovery in most cases. Remarkably, around $10 \%$ of patients do not develop further episodes after the first [4]; but in those who experience persistent illness or recurrences, antipsychotics do not reverse the cognitive deficits and negative symptoms that contribute to most of the functional disability[5,6]. Currently there are no truly 'disease-modifying' interventions available[7] though many promising leads have emerged in recent times.

While a complete mechanistic account of the schizophrenia or the 'group of schizophrenias', as Bleuler surmised 110 years ago[8], is still lacking, 3 key neurobiological substrates of the disabling illness trajectory have emerged in recent times. (1) glutamatergic dysfunction in early stages[9,10] related to excitation-inhibition imbalance resulting from prefrontal parvalbumin interneuron deficits in the cortical microcircuit $[11,12](2)$ dysconnectivity of large-scale brain networks (especially involving the dorsal anterior cingulate cortex [ACC] and insula) in prodromal stages before the first-episode[13-16], 
related to persistent symptom burden[17-19] and cognitive deficits[20-22], and (3) microstructural changes in the grey[23,24] and white matter[25-27], predating the illness but becoming more prominent during the first-episode[24], possibly reflecting the loss of dendritic spines[28,29] and myelination deficits[30,31]. Despite these mechanistic insights no accessible therapeutic targets have emerged yet. This is because most changes occur in early developmental periods that precede the illness onset by many years. By the time symptoms first appear, most neural disruptions are already well established and often irreversible. Therefore, there is an urgent need to identify pathways of poor outcome in schizophrenia that remain 'modifiable' after the symptom onset.

\section{Glutathione in schizophrenia}

One of the pathways of poor outcome that has its roots in early life, but continue to remain modifiable in later stages of illness may be the antioxidant pathway. Destructive free radicals that damage brain tissue are by-products of oxidative metabolism but are effectively scavenged by antioxidants. Glutathione [GSH] is the cardinal antioxidant in brain cells. In preclinical models of schizophrenia, early GSH deficit contributes to dysfunction of prefrontal parvalbumin interneurons[32,33], increased susceptibility of excitotoxic pyramidal cell damage especially in the presence of a hyperdopaminergic state[34,35], reduced dendritic spines[36], reduced stability of axonal projections[37] and facilitates oligodendrocyte cell death disrupting myelin formation [38-41]. Crucially, agents that improve GSH levels ameliorate the effects of oxidative stress in various preclinical models of schizophrenia (ketamine [42], GluN2A[43] or neonatal ventral hippocampal lesions [44,45], perinatal infection[46], stimulant exposure[46], and maternal immune activation[47]). This large body of evidence has led to the claim that various mechanistic strands underlying schizophrenia converge on the "hub of oxidative stress" indexed by GSH[48,49]. Preclinical models with early GSH deficit (i.e. from postnatal day 0 onwards) display various schizophrenia-like features in adult life, including a sensitivity to dopamine excess[50], and prefrontal hypomyelination[51]. Nevertheless, chronic peri-adolescent treatment with the glutathione precursor $\mathrm{N}$-acetylcysteine (postnatal days 5-90) restores antioxidant-related and myelin-related mRNA expression improving cognitive flexibility in later life[51]. Thus, despite the likely developmental origins of the GSH-deficit, a phenotype 'rescue' is possible in preclinical models with interventions in later life. Such 'rescue' effects on myelination have also been reported in patients with early psychosis taking GSH precursors as supplements[52], offering GSHdeficit as a potentially modifiable pathway of poor outcomes in schizophrenia. In this context, early identification of individuals with GSH-deficit from clinical samples of patients with schizophrenia assumes paramount importance.

\section{Intracortical GSH in schizophrenia: MRS studies}

Peripheral antioxidant markers are reduced in patients with schizophrenia[53,54]. Genetic [55,56] and cell biology studies [57-59] indicate that the ability to produce GSH in the face of oxidative stress is likely to be reduced in the patients, at least a subset of them. More direct demonstration of low GSH levels comes from in vivo Magnetic Resonance Spectroscopic (MRS) studies and CSF measurements or post-mortem quantification of glutathione. Early in vivo studies reported 27-52\% GSH reduction[60-62] in established schizophrenia. For many subsequent MRS GSH studies, the anterior cingulate cortex (ACC) has been the chosen region of interest given its relevance to schizophrenia as well as the technical advantage (uniform field homogeneity, higher signal-to-noise, narrow spectral peak width, low probability of susceptibility artefacts) offered by a midline MRS voxel placement[63]. A recent synthesis of cross-sectional MRS studies demonstrated a small but significant GSH reduction (effect size $=0.26$ ) in the ACC region in schizophrenia[64]. Interestingly, of the 12 studies that were included in this meta-analysis, only 2 reported significant GSH differences between patients and HCs[60,65], contributing to a modest reduction in GSH among patients. This small but significant GSH reduction in 
schizophrenia has been reported by 2 other meta-analyses, one restricted to ultra-high field 7T MRS studies (effect size $=0.21$ )[66] and the other including all central measures of GSH MRS, CSF and post-mortem samples (effect size $=0.26$ )[67].

Since 2018, several MRS studies on ACC GSH in schizophrenia have been published [68-74] (Table 1). While the largest study to date supports Das and colleagues' report of GSH reduction in early stages of schizophrenia, smaller studies find no differences in patients when compared to healthy controls. Interestingly, samples of acutely symptomatic, untreated first-episode patients report higher levels of ACC GSH than healthy controls that is not seen in other post-acute samples beyond 1-2 years of illness that are likely to include more treatment-resistant subjects.

These observations present a more nuanced picture of intracortical GSH aberrations than what can be expected from preclinical studies or from the large effect size reduction of peripheral GSH measures in schizophrenia.

Table 1. Studies of intracortical GSH published since Das et al., 2018

\begin{tabular}{|c|c|c|c|c|c|c|c|}
\hline Study & $\begin{array}{l}\text { No. } \\
\text { patients } \\
\text { / } \\
\text { controls }\end{array}$ & $\begin{array}{l}\text { Females / } \\
\text { Males } \\
\text { Patients }\end{array}$ & $\begin{array}{l}\text { No. of } \\
\text { Females / } \\
\text { Males } \\
\text { Controls }\end{array}$ & $\begin{array}{l}\text { Age of } \\
\text { patients } \\
\text { (years) } \\
\text { Mean } \\
(\mathrm{SD})\end{array}$ & $\begin{array}{l}\text { Age of } \\
\text { controls } \\
\text { (years) } \\
\text { Mean (SD) }\end{array}$ & Clinical features & $\begin{array}{l}\text { Duration of } \\
\text { illness } \\
\text { (years) } \\
\text { Mean (SD) }\end{array}$ \\
\hline $\begin{array}{l}\text { Coughlin et al., } \\
2021\end{array}$ & $\begin{array}{l}46 / 50 \\
\left(16 / 10^{*}\right)\end{array}$ & $12 / 34$ & $16 / 34$ & $\begin{array}{l}34.17 \\
(11.8)\end{array}$ & $32.06(11.28)$ & $\begin{array}{l}\text { Chronic, stable phase of } \\
\text { schizophrenia; } 13 \% \text { no APD. } \\
\text { ACC GSH patients = HC }\end{array}$ & $12.36(11.45)$ \\
\hline $\begin{array}{l}\text { Dempster et } \\
\text { al., } 2020^{a}\end{array}$ & $26 / 27$ & $5 / 21$ & $10 / 17$ & $\begin{array}{l}24.04 \\
(5.4)\end{array}$ & $21.48(3.57)$ & $\begin{array}{l}\text { Acute, untreated psychosis; } \\
\text { dACC GSH patients = HC; } \\
\text { Higher GSH in patients with } \\
\text { faster response to APD. }\end{array}$ & $0.54(1.25)$ \\
\hline $\begin{array}{l}\text { Godlewska et } \\
\text { al., } 2021\end{array}$ & $\begin{array}{l}17 / 18 \\
\left(14 / 18^{*}\right)\end{array}$ & $0 / 17$ & $0 / 18$ & $25.6(1.1)$ & $27.1(0.8)$ & $\begin{array}{l}\text { Stabilized first-episode; } \\
\text { diagnostic information N/A; } 12 \% \\
\text { no APD; ACC GSH patients = HC }\end{array}$ & $2.54(0.28)$ \\
\hline $\begin{array}{l}\text { Iwata et al., } \\
2021^{\text {b }}\end{array}$ & $21 / 26$ & $5 / 16$ & $7 / 19$ & $\begin{array}{l}46.3 \\
(12.7)\end{array}$ & $40.8(13.2)$ & $\begin{array}{l}\text { First line treatment responders; } \\
\text { dACC GSH patients = HC }\end{array}$ & $20.0(12.2)$ \\
\hline $\begin{array}{l}\text { Iwata et al., } \\
2021^{\text {b }}\end{array}$ & $27 / 26$ & $8 / 19$ & $7 / 19$ & $\begin{array}{l}40.5 \\
(11.2)\end{array}$ & $40.8(13.2)$ & $\begin{array}{l}\text { TRS -Clozapine responders; } \\
\text { dACC GSH patients = HC }\end{array}$ & $16.4(9.7)$ \\
\hline $\begin{array}{l}\text { Iwata et al., } \\
2021^{\text {b }}\end{array}$ & $24 / 26$ & $5 / 19$ & $7 / 19$ & $\begin{array}{l}44.8 \\
(13.2)\end{array}$ & $40.8(13.2)$ & $\begin{array}{l}\text { TRS - Clozapine non-responders; } \\
\text { dACC GSH patients = HC }\end{array}$ & $23.5(13.2)$ \\
\hline $\begin{array}{l}\text { Limongi et } \\
\text { al., 2021 a }\end{array}$ & $19 / 20$ & $7 / 12$ & $9 / 11$ & $21.7(3.3)$ & $21.3(3.7)$ & $\begin{array}{l}\text { Acute, untreated psychosis; } 60 \% \\
\text { no APD; dACC GSH } \\
\text { patients }>\text { HC }\end{array}$ & 1.1(1.8) \\
\hline $\begin{array}{l}\text { Pan et al., } 2021 \\
\text { a, b }\end{array}$ & $16 / 25$ & $3 / 13$ & $11 / 14$ & $\begin{array}{l}21.81 \\
(3.17)\end{array}$ & $22.12(3.54)$ & 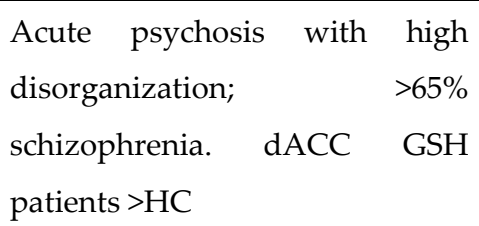 & $0.98(1.13)$ \\
\hline
\end{tabular}




\begin{tabular}{|c|c|c|c|c|c|c|c|}
\hline $\begin{array}{l}\text { Pan et al., } 2021 \\
\text { a, b }\end{array}$ & $24 / 25$ & $6 / 18$ & $11 / 14$ & $\begin{array}{l}23.71 \\
(5.43)\end{array}$ & $22.12(3.54)$ & 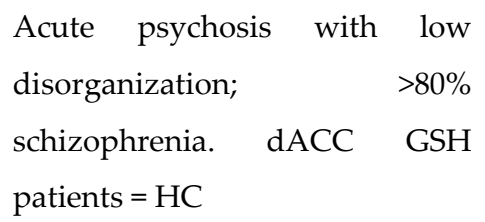 & 0.91(1.7) \\
\hline $\begin{array}{l}\text { Wang et al., } \\
2019\end{array}$ & $\begin{array}{l}81 / 91 \\
\left(74 / 88^{*}\right)\end{array}$ & $24 / 57$ & $49 / 42$ & $22.3[4.4]$ & $23.3(3.9)$ & $\begin{array}{l}\text { Stabilized first-episode; }<65 \% \text { of } \\
\text { sample had schizophrenia. } \\
\text { dACC GSH HC>patients }\end{array}$ & $1.27(0.8)$ \\
\hline \multicolumn{8}{|c|}{$\begin{array}{l}1{ }^{*} \text { Final sample with available MRS glutathione (GSH) data; all demographic information refers to } \\
\text { the original larger sample. a overlapping samples; }{ }^{\text {b }} \text { same healthy control samples, distinct patient } \\
\text { samples, reported in the same manuscript. APD: Antipsychotic Drugs, dACC: Dorsal Anterior } \\
\text { Cingulate Cortex. HC: Healthy control subjects, NA: Data not available; SD: Standard Deviation; } \\
\text { TRS: Treatment Resistant Schizophrenia }\end{array}$} \\
\hline
\end{tabular}

The heterogeneity observed in MRS studies of ACC GSH in schizophrenia highlight two distinct possibilities. Firstly, there are likely at least 2 subgroups of patients, one with notable GSH deficit, and the other with near-normal or supra-normal levels of GSH compared to healthy subjects. Both these subgroups are most likely to be apparent among the untreated first episode patients with more florid positive symptoms but less cognitive deficits and more favourable treatment response profile than more established cases. One of the earliest reports linking increased intracortical GSH with favourable treatment outcomes came from the study of Wood and colleagues[75]. They reported a $22 \%$ increase in medial temporal GSH levels in first episode psychosis; in a sub-sample from this study[76], treatment related increase in GSH was associated with a gain in global functioning scores. ACC GSH levels were not examined in their sample. We observed that in untreated first episode patients, an elevated ACC GSH at the time of presentation occurred in those with more florid disorganization[73] but most of these subjects responded briskly to the regular antipsychotic treatments over the next 6 months[69]. Help seeking subjects with subthreshold psychotic symptoms display better social and occupational functioning when ACC GSH levels are higher [77]. In the metaanalysis of Das and colleagues we noted a small but significant increase in ACC GSH in bipolar disorder, a phenotype that is often associated with better functional outcomes than schizophrenia[64]. Samples with more established schizophrenia with residual symptoms and impaired functioning are likely to have an over-representation of the subgroup with GSH deficit. Based on the reported effect-sizes of the observed GSH deficit across chronic and partially treatment-resistant samples[64,67], it is likely that only a subgroup of patients have a notable GSH-deficit. Nonetheless, this subgroup of patients with GSH-deficit are likely to be treatment-resistant; a recent 7T MRS study in first-episode psychosis reports a large effect-size (Cohen's d $=0.83$ ) reduction in ACC GSH in 32 treatment-resistant patients compared to 106 non-treatment-resistant patients[78].

Second possibility is that in a patient with schizophrenia, GSH levels may vary with the stage of illness. Acute, untreated symptomatic state may relate to higher levels of GSH than stable clinical states of schizophrenia. Increase in GSH level may mark a compensatory response to acute oxidative stress that may not be sustained as the illness progresses to more persistent stage. Longitudinal studies of intracortical GSH are limited; most patient cohorts with repeated MRS acquisitions to date did not measure GSH [79-83]. To our knowledge, only 2 studies report on longitudinal GSH measurements in psychosis to date. In a sample of 21 subjects with first episode schizophrenia scanned at baseline with $<3$ days of lifetime antipsychotic exposure and followed after 6 months of antipsychotic treatment, GSH levels were highly stable $($ Mean(SD) at baseline $=1.71(0.36)$, at 6- 
months $=1.75(0.23))[84]$. The same stability in GSH levels was also seen in the 10 demographically healthy controls scanned at 2 time points (Mean(SD) at baseline $=1.64(0.25)$, at 6 -months $=1.63(0.32)$ ) [84]. In a larger sample of 38 patients with first episode psychosis (onset within 2 years) and 48 healthy controls followed up over 4 years [85], GSH levels was found to have a near zero change in all 5 studied brain regions (ACC, thalamus, DLPFC, centrum semiovale and orbitofrontal cortex) over time, strongly arguing for a 'trait-like' stability of GSH levels compared to other metabolites. These observations do not rule out within-individual differences over time, and the possibility of an early excess in untreated state; but provide a strong support for the presence of a distinct subgroup with GSH-deficit that is over-represented in more established phase of schizophrenia, in association with reduced treatment responsiveness and poor functional outcomes.

In the next 2 sections we focus on factors contributing to the putative intracortical GSHdeficit and the pathophysiological consequences of this deficit.

\section{Factors contributing to the putative intracortical GSH deficit}

Preclinical studies discussed earlier insinuate the possibility of a constitutional defect in GSH synthesis in schizophrenia. Defective production of GSH due to reduced expression of the GSH synthesizing enzyme Glycine Cysteine Ligase (GCL), has been demonstrated in patient-derived cell culture studies[57]. The high-risk variant gene encoding GCL's catalytic subunit (GCLC) with 8 or 9 GAG repeats as opposed to 7) was seen in $36 \%$ of patients, but only $3 \%$ of healthy controls in some samples [57]. Later studies have failed to replicate an association between high-risk GCLC variant and lower GSH levels in schizophrenia $[68,71,86]$. Thus, the high risk variants do not consistently indicate low intracortical GSH[62,87]. In the same vein, low GSH levels in post-mortem brain tissue of patients with schizophrenia are observed despite normal levels of GCL and GSH peroxidase-like protein [88]. Furthermore, large-scale genome-wide association studies (GWASs) to date have not observed aberrations in the GSH synthesis pathway in schizophrenia (reviewed by Ermakov et al.[89]). Thus, a constitutional defect in GSH synthesis, if present, may be limited to a small number of patients. In most others, intracortical GSH levels are likely influenced by indirect factors (e.g., transcriptional regulators or epigenetic factors regulating gene expression $[89,90])$ affecting redox status.

Environmental factors, in particular lifestyle factors, also determine intracortical GSH. In fact a number of lifestyle factors in patients with mental illnesses may transiently affect GSH levels[91,92]. For example, in youth with mood disorders[93], apparent intracortical GSH-deficits are mostly explained by lifestyle factors (alcohol or smoking) $[91,94,95]$. In depression, this early-life reduction in GSH levels[96,97] appears to normalise later (15.7\% increase, 1 year after first-episode depression[98]), likely explaining the higher than expected levels in later life[99]. At present, the relative influence of lifestyle factors on intracortical GSH in schizophrenia is unknown.

While several studies have examined the influence of lifestyle factors on peripheral antioxidant markers [100,101], intracortical GSH levels do not always reflect the peripheral antioxidant status in schizophrenia. For example, while the levels of scavenging antioxidant enzymes such as glutathione peroxidase levels correlate positively with ACC GSH in healthy subjects, such an effect is inconsistent, and absent in patients $[55,86]$. Peripheral antioxidant deficit in schizophrenia is of several magnitudes larger than the central GSH reduction reported so far (effect sizes 1.02 vs 0.26[67]). Further, localised brain tissue changes, such as an increase in free water concentration in grey matter (likely an effect of neuroinflammation), can affect the intracortical GSH in schizophrenia[102]. 


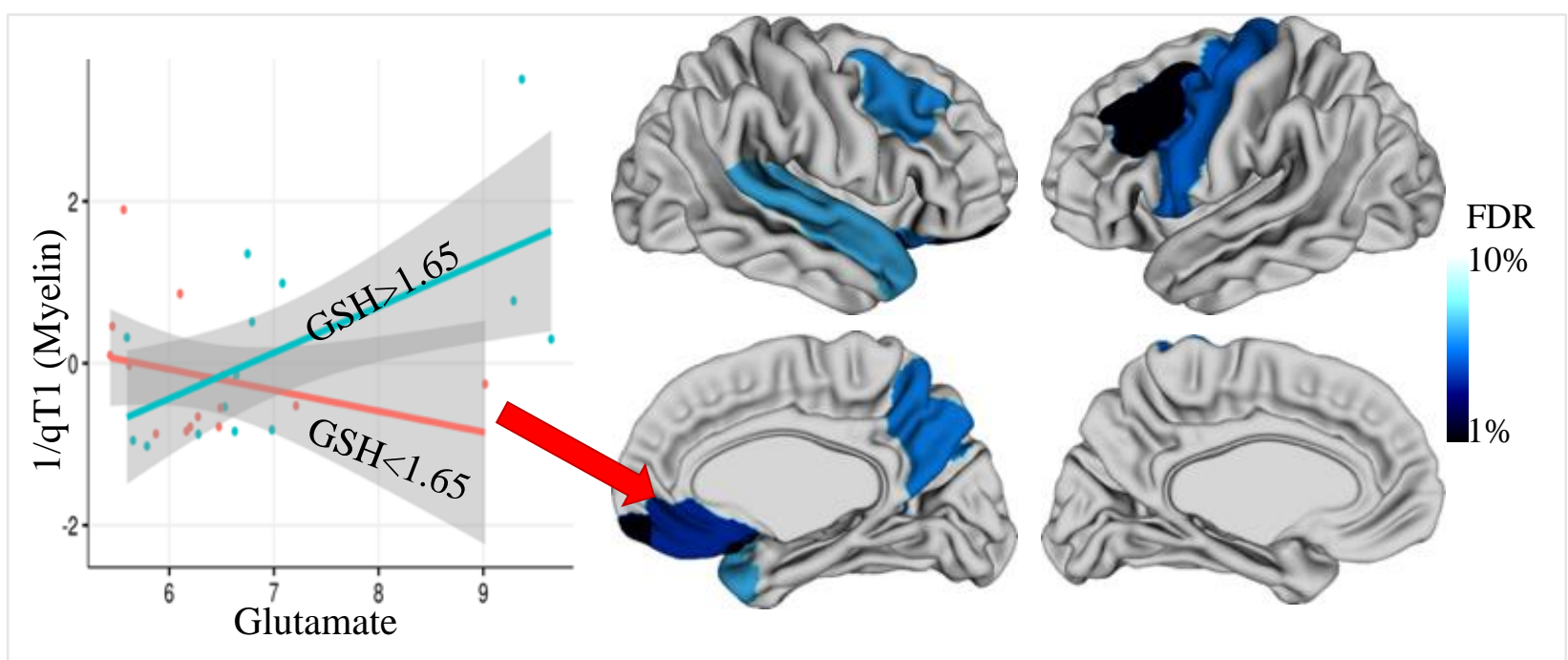

Figure 2: Permissive role of GSH on glutamate-related demyelination. Intracortical myelin (qT1) was mapped at the mid-cortical surface $\quad$ (50\% depth between the white matter an pial surfaces) using the CIVET pipeline (https://github.com/aces/CIVET) with T1-weighted images. Median qT1 values were gathered over cortical regions defined by the Desikan-Killiany Atlas (DKT40). In First Episode Psychosis $(n=30)$, glutamate relates to reduced prefrontal, orbitofrontal, and superior temporal intracortical myelin (1/qT1) only when GSH levels are also lower (red slope) in the dorsal ACC [MRS voxel not shown] results were significant in 8 cortical regions after FDR correction (10\%). Scatterplot shows the right lateral orbitofrontal cortex, indicating significant glutamate-by-GSH interaction effect $\left(\mathrm{t}_{24}=5.59, \mathrm{p}=9.52 \mathrm{E}\right.$ 06) on qT1, accounting for age and sex as covariates in multiple linear regression. Mean age 23.13 (SD 5.30), with 24/6 male/female subjects.

Taken together, intracortical GSH-deficit may represent a 'failure mode' of the redox system occurring in some patients with schizophrenia, with multifactorial pathways (genetic and lifestyle-related) converging to result in a relative GSH-deficit state over the course of this illness.

\section{Consequences of the putative intracortical GSH deficit}

Irrespective of its origins, the presence of a pervasive inability to counter oxidative stress with increased intracortical GSH is likely to produce multiple downstream consequences in schizophrenia. Preclinical studies reviewed above indicate that a GSH-deficit is likely to facilitate excitotoxic damage[34,35] affecting dendritic spines[36] and axonal stability[37] and disrupting myelin formation[38-41]. Myelin deficits in schizophrenia (termed dysmyelination[103,104]) are likely multifactorial[105,106]; oxidative stress is hypothesized to preferentially affect prefrontal myelin-generating precursor cells[107109], affecting cortical microcircuits in early phase of psychosis[49,110]. In first episode schizophrenia, GSH levels correlate with white matter integrity [39]; its relationship with myelin content and microstructure of the grey matter is still unknown. Most of the recorded grey matter changes in schizophrenia occurs in the immediate post-onset phase[24,111,112], coinciding with the critical period of intracortical myelination[113115]. Intracortical myelin mostly insulates parvalbumin containing interneurons[116] that are highly susceptible to GSH deficit and associated glutamate-mediated excitotoxicity $[117,118]$. In a subsample of patients reported by Pan and colleagues[73], we 
obtained quantitative intracortical myelin measurement and noted several regions where patients had lower intracortical myelin in the presence of higher glutamate, only when GSH levels were lower than the median (bilateral dorsolateral prefrontal cortex, right superior temporal and left precentral gyrus and right subgenual ACC). Thus, higher ACC glutamate related to lower prefrontal intracortical myelin, only when ACC GSH levels were also lower, indicating a gatekeeping role for GSH in glutamate-related dysmyelination (Figure 1). Relating GSH-deficit at the onset to subsequent intracortical myelin changes will provide compelling proof for the downstream effects of antioxidant aberrations on the illness trajectory.

In terms of clinical and functional consequences of low intracortical GSH, we observed a predictive relationship between low GSH and delayed response to antipsychotics. For every $10 \%$ move towards the lower end of GSH levels, patients had 7 additional days of non-response to antipsychotics[69]. Lack of early response is a critical indicator of longterm poor outcomes in schizophrenia[119-121]. Significant deficits in ACC GSH observed in patients with early stage of treatment resistance is highly suggestive of a poor outcome trajectory[78]. Correlational studies also relate lower GSH to higher residual symptom burden[65], negative symptoms[122] and cognitive deficits[74] in established cases of schizophrenia.

In summary, patients with intracortical GSH deficit are likely to display structural and functional features indicative of poor outcome trajectories in schizophrenia. Nevertheless, due to the lack of temporal information required to separate causes vs. consequences, it is not clear if low ACC GSH plays a causal role in persistent poor outcome trajectory across the course of schizophrenia[67]. Longitudinal follow-up studies linking baseline GSH measurement to later long-term functional outcome are required in this regard.

\section{Glutathione - glutamate relationship}

In healthy physiological states, ACC GSH and glutamate levels are tightly correlated $[65,68,69]$. This may relate to the co-dependency of intracellular GSH and glutamate synthetic processes, with GSH acting as a reservoir for glutamate[123,124]. If GSH synthesis is reduced by blocking glutamate to GSH conversion, this increases cytosolic glutamate levels and synaptic excitatory potential. On the other hand, if GSH to glutamate conversion is blocked, this reduces glutamate concentration and synaptic excitation. Thus, intracortical GSH levels influence the prevailing glutamatergic tone, and vice versa. This raises the question of whether the subgroup of patients with higher-than-normal GSH levels in early stages of psychosis have a concurrent increase in glutamate levels.

Among the untreated first episode patients, we indeed noted higher glutamate levels in those with higher GSH levels, though this relationship was weaker than in healthy subjects[69]. Higher intracortical glutamate levels relate to reduced social function[69,125] and poorer treatment response[81] in early stages and reduced cortical grey matter $[83,126,127]$. On the other hand, higher GSH levels relate to faster treatment response[69], better functioning[77] and preserved cortical grey matter[102] [See[128,129] for association with peripheral GSH]. We recently observed opposing influence of glutamate and GSH on the intrinsic connectivity within the dACC node of the Salience Network in first episode psychosis [72]. Thus, GSH and glutamate may have contrasting effects on the course of schizophrenia.

In schizophrenia, while the exact nature of glutamate dysfunction in schizophrenia is yet to be clarified, meta- and mega-analyses of MRS data demonstrate a glutamatergic deficit state, at least in the prefrontal cortex $[66,130,131]$. Emerging observations implicate antipsychotics in progressive glutamate reduction in schizophrenia[130] but evidence in 
this regard is still inconclusive (see [84] and [131]). Interestingly, lower GSH levels cooccur with reduced glutamate in the chronic stage $[65,68]$, especially in ultra-treatmentresistant patients [71]. Thus, a GSH-deficit phenotype may be characterised by concurrent reduction in glutamate. This concurrent reduction may reflect a persistent reduction in neural activity. In a healthy physiological state, sustained neural activity inevitably increases mitochondrial oxidative stress; as a result, increase in GSH may occur to reduce free radical burden. This activity-dependent GSH increase has been observed in short time scales (over a few minutes) using functional MRS in several [132-134] but not all [135-137] studies to date. Task-dependent increase in GSH may also reflect an increase in conversion of the excess synaptic glutamate released during sustained neural activity; this diversion to GSH-synthesis can in turn reduce the availability of the precursor glutamate and reduce further excitation. The presence of a negative correlation between BOLD signal and task-related GSH increase[132] further supports this view. In this context, sustained reduction of intracortical GSH may reflect a pervasively low neural activity of a given brain region. Thus, in chronic stages of schizophrenia when sustained effortful activity is diminished, low GSH levels can be expected accompanying a glutamatergic deficit state.

In summary, the fate of GSH and glutamate are highly intertwined throughout the longitudinal trajectory schizophrenia. Delineating the putative functional relevance of intracortical GSH deficit requires concomitantly measuring glutamate to clarify its relationship, as well as tracking the functional outcomes and cumulative treatment exposure[67] in schizophrenia.

\section{Treatment-engagement and stratification markers (GSH) for antioxidant trials}

An exciting clinical utility of prospectively identifying patients with GSH-deficit is the therapeutic possibility of correcting it. A number of compounds with the potential to correct the effects of GSH deficit are in the pipeline (Table 2)[44,76,138-168]. Of these, Nacetylcysteine has been shown to improve cognition and negative symptoms (6 RCTs)[169], though the effect size is modest. Antioxidant therapies are more likely to benefit patients with a central antioxidant-deficit. Reliable characterisation of the GSH-deficit phenotype is critical in this regard. Furthermore, while the antioxidant pipeline is promising[44,76,138-168], reversing cognitive/negative symptoms requires longer trials that are substantially difficult to complete. We need reliable markers of biological efficacy that indicate engagement of the mechanistic target; this will help overcome several obstacles in clinical translation (e.g., targeted in vivo assay, dose finding, estimating trial duration, understanding placebo response). While MRS ACC GSH measurement provides a marker for treatment-engagement[170], given its variation with the illness phase, it is unlikely to become a standalone aid in patient selection for long-term trials. More accessible behavioural readouts (delayed response to antipsychotics or poor social or occupational functioning) may help in patient selection. 


\begin{tabular}{|l|l|}
\hline Drugs that activate Nrf2-mediated GSH regulation & $\begin{array}{l}\text { Drugs that increase or stabilise GSH levels via other } \\
\text { mechanisms }\end{array}$ \\
\hline $\begin{array}{l}\text { Sulforaphane (NCT02880462; NCT02810964; NCT01716858; } \\
\text { NCT04521868) }\end{array}$ & N-acetylcysteine[169,171] [NCT02505477, NCT03149107] \\
\hline Curcumin[151,152] [NCT02104752, NCT02298985] & Direct liposomal GSH[154][NCT01967667] \\
\hline Resveratrol[155,156] & Ebselen[44,143] [NCT03013400] \\
\hline Quercetin[157,158] [NCT04063124], & Ethyl eicosopentanoic acid[76,142] \\
\hline Genistein[159,160] [NCT01982578] & Glucose-dependent insulionotropic polypeptide[140] \\
\hline Andrographolide[161] & Alpha-lipoic acid[141] [NCT03788759] \\
\hline CXA-10[162] & L-arginine[139] [NCT04054973] \\
\hline Bardoxolone[168] & S-adenosylmethionine[146,147] \\
\hline Omaveloxolone[163] [NCT02255435], & Sarcosine [164,165] \\
\hline Sulforadex (SFX-01)[172] [NCT02614742]) & Serine[144,145] [NCT04140773, NCT03711500] \\
\hline Dimethylfumarate[149,150] - now used for MS & Telmisartan[138] [NCT03868839] \\
\hline Luteolin[166,167] & Trehalose[153] [NCT02800161] \\
\hline
\end{tabular}

In terms of neuroimaging-based stratification markers for long-term clinical trials, two promising approaches need further study. One is the use of measures reflecting the likely downstream effects of the GSH-deficit. Given the critical importance of restoring glutamate homeostasis by manipulating GSH levels, indices of glutamatergic dysfunction may prove to be useful indirect markers of the need for antioxidant trials. Using dynamic causal modelling (DCM) of resting state functional MRI, Limongi and colleagues linked higher ACC glutamate in untreated schizophrenia to a model of cortical disinhibition in the ACC-insula network[18]. Glutamate-related disinhibition in this network predicted computational parameters of cognitive dysfunction as well as social withdrawal[18], while GSH levels had a robust relationship with the state of excitation-inhibition imbalance in this assay, with higher GSH predicting reduced disinhibition, an opposite effect from glutamate. An antioxidant that reliably reduces such markers of glutamate-related cortical disinhibition (likely by increasing intracortical GSH) is likely to be 'hitting the target' relevant to schizophrenia.

Another potential stratification marker is the estimation of early 'response' in MRS GSH to antioxidants as an indicator of the likelihood of success of long-term treatment. In essence, this is similar to the use of early symptom reduction as a longer-term prognostic indicator. Several antioxidants act by supplying the precursor for GSH synthesis, taking longer time to increase intracortical GSH. For example, NAC increases intracortical GSH by $23 \%$ in schizophrenia only after 24 weeks but not immediately after administration (single dose effect $=1.3 \%$ increase[173]). In contrast, some antioxidants such as sulforaphane have more rapid and stable effect on GSH levels $[174,175]$ by activating the Nrf2 gene, the most dominant regulator of antioxidant transcription pathways. Sulforaphane is $80 \%$ bioavailable, reaches peak plasma levels $1 \mathrm{~h}$ after oral ingestion, with first-order kinetics [ $\mathrm{t}_{1 / 2} \sim 2.5 \mathrm{~h}, 60 \%$ renal excretion at $8 \mathrm{~h}$ [176], full washout recorded in 35 days[177]] and has already been shown to increase intracortical GSH (using ultra-high field 7T MRS) in healthy volunteers (24\% in 7 days)[178]. It is one of the antioxidants whose pharmacokinetics are well studied[179], safety profile established in clinical trials[180-182] with 4 ongoing trials in schizophrenia, making it a suitable drug to evaluate markers of biological efficacy. A notable sulforaphane-induced increase in MRS GSH level 
may predict a relative deficit state at the baseline, and thus a superior long-term functional response in patients.

\section{Challenges and opportunities}

The extant literature reviewed above indicates that in a latent subgroup of patients with schizophrenia, a pervasive intracortical GSH-deficit may result from a confluence of risk factors. A question of great translational importance is whether we can identify the subgroup of patients who will develop GSH-deficit at the onset of illness. The studies reviewed above suggest that this subgroup cannot be identified simply on the basis of genotyping or peripheral antioxidant measurements alone[67]. We suggest the following approaches for a reliable characterization of a pervasive intracortical GSH-deficit subtype:

1. The putative consequences of GSH-deficit in schizophrenia likely involve aberrant functional connectivity within key brain networks (e.g., the Salience Network for dorsal ACC GSH deficit), myelination as well as grey matter microstructure. Longitudinal multimodal imaging, preferably starting from untreated states, and experimental 'perturband-measure' approaches with pharmacological agents such as sulforaphane or NAC will provide the required temporal information to characterize a causal role for intracortical GSH on these features. This is essential to establish the biological construct validity of the GSH-deficit phenotype in vivo.

2. Attrition of the inception cohort is an important challenge in longitudinal studies of early-stage psychosis. Multi-site involvement is likely to be of critical importance to overcome this issue.

3. Subgroup identification based on continuous biological measures is a statistical challenge; a single cut-off value for clinical decisions may not readily emerge. To mitigate this, in addition to the use of growth mixture and clustering models, normative estimates of MRS GSH values and classification approaches to inform cutoff optimization may be required.

4. Several potential confounders/mediators of intracortical GSH (lifestyle variables, genetic variants, antipsychotic/antidepressant exposure, duration of illness, and substance use) require careful quantification to establish a relationship with outcomes of interest.

5. Isolated measures of intracortical GSH does not provide the context in which the observed reduction occurs; concurrent static or dynamic measurement of glutamate will provide the relevant information to study putative mechanistic changes. As of now, 7TMR spectroscopy (MRS), with its attendant improvisation in signal detection hardware, pulse sequences and spectral modelling, is positioned as the only human in-vivo technique that can confidently isolate glutamate from other molecules and concurrently estimate glutathione resonance. Among the MRS studies specifically optimized for GSH detection, 7T studies $[65,183]$ report higher effect sizes GSH reduction in schizophrenia compared to $3 \mathrm{~T}[55,184]$

Current methods for measuring human brain intracortical GSH levels via MRS in conjunction with other critically relevant metabolites of the cortical microcircuit such as glutamate and GABA currently have quantification precision in the range of $20-40 \%$. The use of MRS methods optimized for one of these key metabolites improves the quantification precision below $10 \%$ for one metabolite at the detriment of others (see [185] for a detailed review). Some recent developments to study redox status in vivo utilizing hyperpolarized ${ }^{13} \mathrm{C} \mathrm{N}$-acetyl cysteine [186,187] or thiol-water proton exchange saturation transfer are promising to extend our insights into the glutathione system. Ultimately, developing MRS simultaneously optimized to provide quantification precision better than $10 \%$ for 
GSH, glutamate as well as GABA with greater spatial precision will open opportunities to explore mechanistic interventions targeting the schizophrenia redox-dysregulation subtype.

On the translational front, characterizing a redox-dysregulation subtype of schizophrenia using GSH-centered imaging holds significant promise for early intervention. Unlike data-driven subtyping approaches that are currently prevalent in the field, the redoxdysregulation or GSH-deficit subtype is based on the prediction of varying psychopharmacological outcomes i.e., superior response to antioxidants/ poor response to antipsychotics. This may open up the possibility of a stratified approach to pharmacological intervention in one subgroup and may reduce the iatrogenic burden of blanket trials across an entire diagnostic group over long time periods. Identifying reliable peripheral proxies for intracortical GSH will move this quest even closer to our clinics[188,189].

The GSH-deficit hypothesis offers a clinically actionable prognostic model in schizophrenia with a well-defined therapeutic utility. Longitudinal multimodal imaging studies combined with experimental 'perturb-and-measure' approaches can help delineate a putative redox-dysregulated subtype and establish its mechanistic primacy in the long-term trajectory of schizophrenia. This approach, if successful, will be a decisive step towards non-dopaminergic early intervention in schizophrenia.

Author Contributions: “Conceptualization, LP.; writing - original draft preparation, LP.; writingreview and editing, all authors.; visualization, MTMP; supervision, LP; funding acquisition, LP. All authors have read and agreed to the published version of the manuscript.

Funding: LP acknowledges support from the Tanna Schulich Chair of Neuroscience and Mental Health. Data reported in figure 2 comes from a study funded by CIHR Foundation Grant (375104/2017) to LP; Grad student salary support of PJ by NSERC Discovery Grant (No. RGPIN201605055) to JT. Data acquisition was supported by the Canada First Excellence Research Fund to BrainSCAN, Western University (Imaging Core); Compute Canada Resources (Application No. 1530) were used in the storage and analysis of imaging data. AS is supported by National Institutes of Mental Health Grants MH-092443, MH-094268, MH-105660, and MH-107730; as well as foundation grants from Stanley and RUSK/S-R. KY is supported by a NARSAD young investigator award from Brain and Behavior Research Foundation.

Institutional Review Board Statement: Not applicable for this review

Informed Consent Statement: Not applicable for this review

Data Availability Statement: The secondary data used in this review is available from the corresponding author upon reasonable request, within the ethics board stipulations.

Acknowledgments: LP is grateful to Michael Mackinley (University of Western Ontario) and Kara Dempster (Dalhousie University) for their assistance with clinical recruitment for the data reported in figure 2.

Conflicts of Interest: LP receives book royalties from Oxford University Press and income from the SPMM MRCPsych course. LP has received investigator-initiated educational grants from Otsuka, Janssen and Sunovion Canada and speaker fee from Otsuka and Janssen Canada, and Canadian Psychiatric Association in the last 3 years. All other authors (Park, Jeon, Limongi, Yang, Sawa, Théberge) report no conflicts of interests. 


\section{References}

1. Jääskeläinen, E.; Juola, P.; Hirvonen, N.; McGrath, J.J.; Saha, S.; Isohanni, M.; Veijola, J.; Miettunen, J. A Systematic Review and Meta-Analysis of Recovery in Schizophrenia. Schizophr. Bull. 2013, 39, 1296-1306, doi:10.1093/schbul/sbs130.

2. Norman, R.M.G.; MacDougall, A.; Manchanda, R.; Harricharan, R. An Examination of Components of Recovery after Five Years of Treatment in an Early Intervention Program for Psychosis. Schizophr. Res. 2018, 195, 469-474, doi:10.1016/j.schres.2017.08.054.

3. Hjorthøj, C.; Stürup, A.E.; McGrath, J.J.; Nordentoft, M. Years of Potential Life Lost and Life Expectancy in Schizophrenia: A Systematic Review and Meta-Analysis. Lancet Psychiatry 2017, 4, 295-301, doi:10.1016/S2215-0366(17)30078-0.

4. $\quad$ Alvarez-Jimenez, M.; Gleeson, J.F.; Henry, L.P.; Harrigan, S.M.; Harris, M.G.; Amminger, G.P.; Killackey, E.; Yung, A.R.; Herrman, H.; Jackson, H.J.; et al. Prediction of a Single Psychotic Episode: A 7.5-Year, Prospective Study in First-Episode Psychosis. Schizophr. Res. 2011, 125, 236-246, doi:10.1016/j.schres.2010.10.020.

5. Fervaha, G.; Foussias, G.; Agid, O.; Remington, G. Impact of Primary Negative Symptoms on Functional Outcomes in Schizophrenia. Eur. Psychiatry J. Assoc. Eur. Psychiatr. 2014, 29, 449-455, doi:10.1016/j.eurpsy.2014.01.007.

6. Addington, J.; Piskulic, D.; Marshall, C. Psychosocial Treatments for Schizophrenia. Curr. Dir. Psychol. Sci. 2010, 19, 260-263, doi:10.1177/0963721410377743.

7. Millan, M.J.; Andrieux, A.; Bartzokis, G.; Cadenhead, K.; Dazzan, P.; Fusar-Poli, P.; Gallinat, J.; Giedd, J.; Grayson, D.R.; Heinrichs, M.; et al. Altering the Course of Schizophrenia: Progress and Perspectives. Nat. Rev. Drug Discov. 2016, 15, 485515, doi:10.1038/nrd.2016.28.

8. Bleuler, E. Dementia Praecox: Or the Group of Schizophrenias (Translated by Zinkin, J.); International Universities Press, 1950;

9. Théberge, J.; Bartha, R.; Drost, D.J.; Menon, R.S.; Malla, A.; Takhar, J.; Neufeld, R.W.; Rogers, J.; Pavlosky, W.; Schaefer, B.; et al. Glutamate and Glutamine Measured with 4.0 T Proton MRS in Never-Treated Patients with Schizophrenia and Healthy Volunteers. Am. J. Psychiatry 2002, 159, 1944-1946, doi:10.1176/appi.ajp.159.11.1944.

10. Coyle, J.T.; Ruzicka, W.B.; Balu, D.T. Fifty Years of Research on Schizophrenia: The Ascendance of the Glutamatergic Synapse. Am. J. Psychiatry 2020, 177, 1119-1128, doi:10.1176/appi.ajp.2020.20101481.

11. Kehrer, C.; Maziashvili, N.; Dugladze, T.; Gloveli, T. Altered Excitatory-Inhibitory Balance in the NMDA-Hypofunction Model of Schizophrenia. Front. Mol. Neurosci. 2008, 1, doi:10.3389/neuro.02.006.2008.

12. Dienel, S.J.; Lewis, D.A. Alterations in Cortical Interneurons and Cognitive Function in Schizophrenia. Neurobiol. Dis. 2019, 131, 104208, doi:10.1016/j.nbd.2018.06.020.

13. Wotruba, D.; Michels, L.; Buechler, R.; Metzler, S.; Theodoridou, A.; Gerstenberg, M.; Walitza, S.; Kollias, S.; Rössler, W.; Heekeren, K. Aberrant Coupling Within and Across the Default Mode, Task-Positive, and Salience Network in Subjects at Risk for Psychosis. Schizophr. Bull. 2014, 40, 1095-1104, doi:10.1093/schbul/sbt161.

14. Guo, S.; He, N.; Liu, Z.; Linli, Z.; Tao, H.; Palaniyappan, L. Brain-Wide Functional Dysconnectivity in Schizophrenia: Parsing Diathesis, Resilience, and the Effects of Clinical Expression. Can. J. Psychiatry 2020, 65, 21-29, doi:10.1177/0706743719890174.

15. Del Fabro, L.; Schmidt, A.; Fortea, L.; Delvecchio, G.; D’Agostino, A.; Radua, J.; Borgwardt, S.; Brambilla, P. Functional Brain Network Dysfunctions in Subjects at High-Risk for Psychosis: A Meta-Analysis of Resting-State Functional Connectivity. Neurosci. Biobehav. Rev. 2021, 128, 90-101, doi:10.1016/j.neubiorev.2021.06.020.

16. Bolton, T.A.W.; Wotruba, D.; Buechler, R.; Theodoridou, A.; Michels, L.; Kollias, S.; Rössler, W.; Heekeren, K.; Van De Ville, D. Triple Network Model Dynamically Revisited: Lower Salience Network State Switching in Pre-Psychosis. Front. Physiol. 2020, 11, 66, doi:10.3389/fphys.2020.00066.

17. Supekar, K.; Cai, W.; Krishnadas, R.; Palaniyappan, L.; Menon, V. Dysregulated Brain Dynamics in a Triple-Network Saliency Model of Schizophrenia and Its Relation to Psychosis. Biol. Psychiatry 2019, 85, 60-69, doi:10.1016/j.biopsych.2018.07.020. 
18. Limongi, R.; Jeon, P.; Mackinley, M.; Das, T.; Dempster, K.; Théberge, J.; Bartha, R.; Wong, D.; Palaniyappan, L. Glutamate and Dysconnection in the Salience Network: Neurochemical, Effective Connectivity, and Computational Evidence in Schizophrenia. Biol. Psychiatry 2020, 88, 273-281, doi:10.1016/j.biopsych.2020.01.021.

19. Palaniyappan, L.; Simmonite, M.; White, T.P.; Liddle, E.B.; Liddle, P.F. Neural Primacy of the Salience Processing System in Schizophrenia. Neuron 2013, 79, 814-828, doi:10.1016/j.neuron.2013.06.027.

20. Luo, Q.; Pan, B.; Gu, H.; Simmonite, M.; Francis, S.; Liddle, P.F.; Palaniyappan, L. Effective Connectivity of the Right Anterior Insula in Schizophrenia: The Salience Network and Task-Negative to Task-Positive Transition. NeuroImage Clin. 2020, 28, 102377, doi:10.1016/j.nicl.2020.102377.

21. Peters, S.K.; Dunlop, K.; Downar, J. Cortico-Striatal-Thalamic Loop Circuits of the Salience Network: A Central Pathway in Psychiatric Disease and Treatment. Front. Syst. Neurosci. 2016, 10, doi:10.3389/fnsys.2016.00104.

22. Moran, L.V.; Tagamets, M.A.; Sampath, H.; O’Donnell, A.; Stein, E.A.; Kochunov, P.; Hong, L.E. Disruption of Anterior Insula Modulation of Large-Scale Brain Networks in Schizophrenia. Biol. Psychiatry 2013, doi:10.1016/j.biopsych.2013.02.029.

23. Nazeri, A.; Mulsant, B.H.; Rajji, T.K.; Levesque, M.L.; Pipitone, J.; Stefanik, L.; Shahab, S.; Roostaei, T.; Wheeler, A.L.; Chavez, S.; et al. Gray Matter Neuritic Microstructure Deficits in Schizophrenia and Bipolar Disorder. Biol. Psychiatry 2017, 82, 726736, doi:10.1016/j.biopsych.2016.12.005.

24. Palaniyappan, L. Progressive Cortical Reorganisation: A Framework for Investigating Structural Changes in Schizophrenia. Neurosci. Biobehav. Rev. 2017, 79, 1-13.

25. Voineskos, A.N.; Lobaugh, N.J.; Bouix, S.; Rajji, T.K.; Miranda, D.; Kennedy, J.L.; Mulsant, B.H.; Pollock, B.G.; Shenton, M.E. Diffusion Tensor Tractography Findings in Schizophrenia Across the Adult Lifespan. Brain 2010, 133, 1494-1504, doi:10.1093/brain/awq040.

26. Kumar, J.; Iwabuchi, S.; Oowise, S.; Balain, V.; Palaniyappan, L.; Liddle, P.F. Shared White Matter Dysconnectivity in Schizophrenia and Bipolar Disorder with Psychosis. Psychol. Med. 2015, 45, 759-770, doi:10.1017/S0033291714001810.

27. Kraguljac, N.V.; Monroe, W.S.; Anthony, T.; Jindal, R.D.; Hill, H.; Lahti, A.C. Neurite Orientation Dispersion and Density Imaging (NODDI) and Duration of Untreated Psychosis in Antipsychotic Medication-Naïve First Episode Psychosis Patients. Neuroimage Rep. 2021, 1, 100005, doi:10.1016/j.ynirp.2021.100005.

28. Bennett, M.R. Schizophrenia: Susceptibility Genes, Dendritic-Spine Pathology and Gray Matter Loss. Prog. Neurobiol. 2011, 95, 275-300, doi:10.1016/j.pneurobio.2011.08.003.

29. Moyer, C.E.; Shelton, M.A.; Sweet, R.A. Dendritic Spine Alterations in Schizophrenia. Neurosci. Lett. 2015, 601, 46-53, doi:10.1016/j.neulet.2014.11.042.

30. Stedehouder, J.; Kushner, S.A. Myelination of Parvalbumin Interneurons: A Parsimonious Locus of Pathophysiological Convergence in Schizophrenia. Mol. Psychiatry 2017, 22, 4-12, doi:10.1038/mp.2016.147.

31. Wei, W.; Zhang, Y.; Li, Y.; Meng, Y.; Li, M.; Wang, Q.; Deng, W.; Ma, X.; Palaniyappan, L.; Zhang, N.; et al. Depth-Dependent Abnormal Cortical Myelination in First-Episode Treatment-Naïve Schizophrenia. Hum. Brain Mapp. 2020, 41, 2782-2793, doi:10.1002/hbm.24977.

32. Cabungcal, J.-H.; Steullet, P.; Kraftsik, R.; Cuenod, M.; Do, K.Q. A Developmental Redox Dysregulation Leads to SpatioTemporal Deficit of Parvalbumin Neuron Circuitry in a Schizophrenia Mouse Model. Schizophr. Res. 2019, 213, 96-106, doi:10.1016/j.schres.2019.02.017.

33. Cabungcal, J.-H.; Steullet, P.; Morishita, H.; Kraftsik, R.; Cuenod, M.; Hensch, T.K.; Do, K.Q. Perineuronal Nets Protect FastSpiking Interneurons against Oxidative Stress. Proc. Natl. Acad. Sci. 2013, 110, 9130-9135, doi:10.1073/pnas.1300454110.

34. Górny, M.; Bilska-Wilkosz, A.; Iciek, M.; Hereta, M.; Kamińska, K.; Kamińska, A.; Chwatko, G.; Rogóż, Z.; Lorenc-Koci, E. Alterations in the Antioxidant Enzyme Activities in the Neurodevelopmental Rat Model of Schizophrenia Induced by Glutathione Deficiency during Early Postnatal Life. Antioxidants 2020, 9, 538, doi:10.3390/antiox9060538. 
35. Grima, G.; Benz, B.; Parpura, V.; Cuénod, M.; Do, K.Q. Dopamine-Induced Oxidative Stress in Neurons with Glutathione Deficit: Implication for Schizophrenia. Schizophr. Res. 2003, 62, 213-224.

36. Fernandez-Fernandez, S.; Bobo-Jimenez, V.; Requejo-Aguilar, R.; Gonzalez-Fernandez, S.; Resch, M.; Carabias-Carrasco, M.; Ros, J.; Almeida, A.; Bolaños, J.P. Hippocampal Neurons Require a Large Pool of Glutathione to Sustain Dendrite Integrity and Cognitive Function. Redox Biol. 2018, 19, 52-61, doi:10.1016/j.redox.2018.08.003.

37. Smith, G.A.; Lin, T.-H.; Sheehan, A.E.; Van der Goes van Naters, W.; Neukomm, L.J.; Graves, H.K.; Bis-Brewer, D.M.; Züchner, S.; Freeman, M.R. Glutathione S-Transferase Regulates Mitochondrial Populations in Axons through Increased Glutathione Oxidation. Neuron 2019, 103, 52-65.e6, doi:10.1016/j.neuron.2019.04.017.

38. Back, S.A.; Gan, X.; Li, Y.; Rosenberg, P.A.; Volpe, J.J. Maturation-Dependent Vulnerability of Oligodendrocytes to Oxidative Stress-Induced Death Caused by Glutathione Depletion. J. Neurosci. Off. J. Soc. Neurosci. 1998, 18, 6241-6253.

39. Monin, A.; Baumann, P.S.; Griffa, A.; Xin, L.; Mekle, R.; Fournier, M.; Butticaz, C.; Klaey, M.; Cabungcal, J.H.; Steullet, P.; et al. Glutathione Deficit Impairs Myelin Maturation: Relevance for White Matter Integrity in Schizophrenia Patients. Mol. Psychiatry 2015, 20, 827-838, doi:10.1038/mp.2014.88.

40. Corcoba, A.; Steullet, P.; Duarte, J.M.N.; Looij, Y.V. de; Monin, A.; Cuenod, M.; Gruetter, R.; Do, K.Q. Glutathione Deficit Affects the Integrity and Function of the Fimbria/Fornix and Anterior Commissure in Mice: Relevance for Schizophrenia. Int. J. Neuropsychopharmacol. 2016, 19, pyv110, doi:10.1093/ijnp/pyv110.

41. Kilanczyk, E.; Saraswat Ohri, S.; Whittemore, S.R.; Hetman, M. Antioxidant Protection of NADPH-Depleted Oligodendrocyte Precursor Cells Is Dependent on Supply of Reduced Glutathione. ASN NEURO 2016, 8, doi:10.1177/1759091416660404.

Phensy, A.; Duzdabanian, H.E.; Brewer, S.; Panjabi, A.; Driskill, C.; Berz, A.; Peng, G.; Kroener, S. Antioxidant Treatment with N-Acetyl Cysteine Prevents the Development of Cognitive and Social Behavioral Deficits That Result from Perinatal Ketamine Treatment. Front. Behav. Neurosci. 2017, 11, 106, doi:10.3389/fnbeh.2017.00106.

43. Cardis, R.; Cabungcal, J.-H.; Dwir, D.; Do, K.Q.; Steullet, P. A Lack of GluN2A-Containing NMDA Receptors Confers a Vulnerability to Redox Dysregulation: Consequences on Parvalbumin Interneurons, and Their Perineuronal Nets. Neurobiol. Dis. 2018, 109, 64-75, doi:10.1016/j.nbd.2017.10.006.

44. Cabungcal, J.-H.; Counotte, D.S.; Lewis, E.M.; Tejeda, H.A.; Piantadosi, P.; Pollock, C.; Calhoon, G.G.; Sullivan, E.M.; Presgraves, E.; Kil, J.; et al. Juvenile Antioxidant Treatment Prevents Adult Deficits in a Developmental Model of Schizophrenia. Neuron 2014, 83, 1073-1084, doi:10.1016/j.neuron.2014.07.028.

45. Rao, K.N.; Sentir, A.M.; Engleman, E.A.; Bell, R.L.; Hulvershorn, L.A.; Breier, A.; Chambers, R.A. Toward Early Estimation and Treatment of Addiction Vulnerability: Radial Arm Maze and N-Acetyl Cysteine before Cocaine Sensitization or Nicotine Self-Administration in Neonatal Ventral Hippocampal Lesion Rats. Psychopharmacology (Berl.) 2016, 233, 3933-3945, doi:10.1007/s00213-016-4421-8.

46. Swanepoel, T.; Möller, M.; Harvey, B.H. N-Acetyl Cysteine Reverses Bio-Behavioural Changes Induced by Prenatal Inflammation, Adolescent Methamphetamine Exposure and Combined Challenges. Psychopharmacology (Berl.) 2018, 235, 351368, doi:10.1007/s00213-017-4776-5.

47. Monte, A.S.; Mello, B.S.F.; Borella, V.C.M.; da Silva Araujo, T.; da Silva, F.E.R.; Sousa, F.C.F. de; de Oliveira, A.C.P.; Gama, C.S.; Seeman, M.V.; Vasconcelos, S.M.M.; et al. Two-Hit Model of Schizophrenia Induced by Neonatal Immune Activation and Peripubertal Stress in Rats: Study of Sex Differences and Brain Oxidative Alterations. Behav. Brain Res. 2017, 331, 30-37, doi:10.1016/j.bbr.2017.04.057.

48. Steullet, P.; Cabungcal, J.H.; Monin, A.; Dwir, D.; O’Donnell, P.; Cuenod, M.; Do, K.Q. Redox Dysregulation, Neuroinflammation, and NMDA Receptor Hypofunction: A “Central Hub" in Schizophrenia Pathophysiology? Schizophr. Res. 2016, 176, 41-51, doi:10.1016/j.schres.2014.06.021.

49. Maas, D.A.; Vallès, A.; Martens, G.J.M. Oxidative Stress, Prefrontal Cortex Hypomyelination and Cognitive Symptoms in Schizophrenia. Transl. Psychiatry 2017, 7, e1171-e1171, doi:10.1038/tp.2017.138. 
50. Lech, M.A.; Leśkiewicz, M.; Kamińska, K.; Rogóż, Z.; Lorenc-Koci, E. Glutathione Deficiency during Early Postnatal Development Causes Schizophrenia-Like Symptoms and a Reduction in BDNF Levels in the Cortex and Hippocampus of Adult Sprague-Dawley Rats. Int. J. Mol. Sci. 2021, 22, 6171, doi:10.3390/ijms22126171.

51. Maas, D.A.; Eijsink, V.D.; van Hulten, J.A.; Panic, R.; De Weerd, P.; Homberg, J.R.; Vallès, A.; Nait-Oumesmar, B.; Martens, G.J.M. Antioxidant Treatment Ameliorates Prefrontal Hypomyelination and Cognitive Deficits in a Rat Model of Schizophrenia. Neuropsychopharmacology 2021, 1-11, doi:10.1038/s41386-021-00964-0.

52. Klauser, P.; Xin, L.; Fournier, M.; Griffa, A.; Cleusix, M.; Jenni, R.; Cuenod, M.; Gruetter, R.; Hagmann, P.; Conus, P.; et al. N -Acetylcysteine Add-on Treatment Leads to an Improvement of Fornix White Matter Integrity in Early Psychosis: A DoubleBlind Randomized Placebo-Controlled Trial. Transl. Psychiatry 2018, 8, 220, doi:10.1038/s41398-018-0266-8.

53. Flatow, J.; Buckley, P.; Miller, B.J. Meta-Analysis of Oxidative Stress in Schizophrenia. Biol. Psychiatry 2013, 74, 400-409, doi:10.1016/j.biopsych.2013.03.018.

54. Perkins, D.O.; Jeffries, C.D.; Do, K.Q. Potential Roles of Redox Dysregulation in the Development of Schizophrenia. Biol. Psychiatry 2020, 88, 326-336, doi:10.1016/j.biopsych.2020.03.016.

55. Xin, L.; Mekle, R.; Fournier, M.; Baumann, P.S.; Ferrari, C.; Alameda, L.; Jenni, R.; Lu, H.; Schaller, B.; Cuenod, M.; et al. Genetic Polymorphism Associated Prefrontal Glutathione and Its Coupling With Brain Glutamate and Peripheral Redox Status in Early Psychosis. Schizophr. Bull. 2016, 42, 1185-1196, doi:10.1093/schbul/sbw038.

56. Kim, S.K.; Kang, S.W.; Chung, J.-H.; Park, H.J.; Cho, K.B.; Park, M.-S. Genetic Polymorphisms of Glutathione-Related Enzymes (GSTM1, GSTT1, and GSTP1) and Schizophrenia Risk: A Meta-Analysis. Int. J. Mol. Sci. 2015, 16, 19602-19611, doi:10.3390/ijms160819602.

57. Gysin, R.; Kraftsik, R.; Sandell, J.; Bovet, P.; Chappuis, C.; Conus, P.; Deppen, P.; Preisig, M.; Ruiz, V.; Steullet, P.; et al. Impaired Glutathione Synthesis in Schizophrenia: Convergent Genetic and Functional Evidence. Proc. Natl. Acad. Sci. 2007, 104, 16621-16626, doi:10.1073/pnas.0706778104.

58. Tosic, M. Schizophrenia and Oxidative Stress: Glutamate Cysteine Ligase Modifier as a Susceptibility Gene. Am. J. Hum. Genet. 2006, 79, 586-592.

59. Matigian, N.; Abrahamsen, G.; Sutharsan, R.; Cook, A.L.; Vitale, A.M.; Nouwens, A.; Bellette, B.; An, J.; Anderson, M.; Beckhouse, A.G.; et al. Disease-Specific, Neurosphere-Derived Cells as Models for Brain Disorders. Dis. Model. Mech. 2010, 3, 785-798, doi:10.1242/dmm.005447.

60. Do, K.Q.; Trabesinger, A.H.; Kirsten-Krüger, M.; Lauer, C.J.; Dydak, U.; Hell, D.; Holsboer, F.; Boesiger, P.; Cuénod, M. Schizophrenia: Glutathione Deficit in Cerebrospinal Fluid and Prefrontal Cortex in Vivo. Eur. J. Neurosci. 2000, 12, 3721-3728, doi:10.1046/j.1460-9568.2000.00229.x.

61. Yao, J.K.; Leonard, S.; Reddy, R. Altered Glutathione Redox State in Schizophrenia. Dis. Markers 2006, 22, 83-93.

62. Gawryluk, J.W. Decreased Levels of Glutathione, the Major Brain Antioxidant, in Post-Mortem Prefrontal Cortex from Patients with Psychiatric Disorders. Int. J. Neuropsychopharmacol. 2011, 14, 123-130.

63. Bertholdo, D.; Watcharakorn, A.; Castillo, M. Brain Proton Magnetic Resonance Spectroscopy: Introduction and Overview. Neuroimaging Clin. N. Am. 2013, 23, 359-380, doi:10.1016/j.nic.2012.10.002.

64. Das, T.K.; Javadzadeh, A.; Dey, A.; Sabesan, P.; Théberge, J.; Radua, J.; Palaniyappan, L. Antioxidant Defense in Schizophrenia and Bipolar Disorder: A Meta-Analysis of MRS Studies of Anterior Cingulate Glutathione. Prog. Neuropsychopharmacol. Biol. Psychiatry 2019, 91, 94-102, doi:10.1016/j.pnpbp.2018.08.006.

65. Kumar, J.; Liddle, E.B.; Fernandes, C.C.; Palaniyappan, L.; Hall, E.L.; Robson, S.E.; Simmonite, M.; Fiesal, J.; Katshu, M.Z.; Qureshi, A.; et al. Glutathione and Glutamate in Schizophrenia: A 7T MRS Study. Mol. Psychiatry 2020, 25, 873-882, doi:10.1038/s41380-018-0104-7.

66. Sydnor, V.J.; Roalf, D.R. A Meta-Analysis of Ultra-High Field Glutamate, Glutamine, GABA and Glutathione 1HMRS in Psychosis: Implications for Studies of Psychosis Risk. Schizophr. Res. 2020, 226, 61-69, doi:10.1016/j.schres.2020.06.028. 
67. Tsugawa, S.; Noda, Y.; Tarumi, R.; Mimura, Y.; Yoshida, K.; Iwata, Y.; Elsalhy, M.; Kuromiya, M.; Kurose, S.; Masuda, F.; et al. Glutathione Levels and Activities of Glutathione Metabolism Enzymes in Patients with Schizophrenia: A Systematic Review and Meta-Analysis. J. Psychopharmacol. (Oxf.) 2019, 33, 1199-1214, doi:10.1177/0269881119845820.

68. Coughlin, J.M.; Yang, K.; Marsman, A.; Pradhan, S.; Wang, M.; Ward, R.E.; Bonekamp, S.; Ambinder, E.B.; Higgs, C.P.; Kim, P.K.; et al. A Multimodal Approach to Studying the Relationship between Peripheral Glutathione, Brain Glutamate, and Cognition in Health and in Schizophrenia. Mol. Psychiatry 2020, doi:10.1038/s41380-020-00901-5.

69. Dempster, K.; Jeon, P.; MacKinley, M.; Williamson, P.; Théberge, J.; Palaniyappan, L. Early Treatment Response in First Episode Psychosis: A 7-T Magnetic Resonance Spectroscopic Study of Glutathione and Glutamate. Mol. Psychiatry 2020, 25, 1640-1650, doi:10.1038/s41380-020-0704-x.

70. Godlewska, B.R.; Minichino, A.; Emir, U.; Angelescu, I.; Lennox, B.; Micunovic, M.; Howes, O.; Cowen, P.J. Brain Glutamate Concentration in Men with Early Psychosis: A Magnetic Resonance Spectroscopy Case-Control Study at 7 T. Transl. Psychiatry 2021, 11, 1-7, doi:10.1038/s41398-021-01477-6.

71. Iwata, Y.; Nakajima, S.; Plitman, E.; Truong, P.; Bani-Fatemi, A.; Caravaggio, F.; Kim, J.; Shah, P.; Mar, W.; Chavez, S.; et al. Glutathione Levels and Glutathione-Glutamate Correlation in Patients with Treatment-Resistant Schizophrenia. Schizophr. Bull. Open 2021, doi:10.1093/schizbullopen/sgab006.

72. Limongi, R.; Jeon, P.; Théberge, J.; Palaniyappan, L. Counteracting Effects of Glutathione on the Glutamate-Driven Excitation/Inhibition Imbalance in First-Episode Schizophrenia: A 7T MRS and Dynamic Causal Modeling Study. Antioxidants 2021, 10, 75, doi:10.3390/antiox10010075.

73. Pan, Y.; Dempster, K.; Jeon, P.; Théberge, J.; Khan, A.R.; Palaniyappan, L. Acute Conceptual Disorganization in Untreated First-Episode Psychosis: A Combined Magnetic Resonance Spectroscopy and Diffusion Imaging Study of the Cingulum. J. Psychiatry Neurosci. JPN 2021, 46, E337-E346, doi:10.1503/jpn.200167.

74. Wang, A.M.; Pradhan, S.; Coughlin, J.M.; Trivedi, A.; DuBois, S.L.; Crawford, J.L.; Sedlak, T.W.; Nucifora, F.C.; Nestadt, G.; Nucifora, L.G.; et al. Assessing Brain Metabolism With 7-T Proton Magnetic Resonance Spectroscopy in Patients With FirstEpisode Psychosis. JAMA Psychiatry 2019, doi:10.1001/jamapsychiatry.2018.3637.

75. Wood, S.J.; Berger, G.E.; Wellard, R.M.; Proffitt, T.-M.; McConchie, M.; Berk, M.; McGorry, P.D.; Pantelis, C. Medial Temporal Lobe Glutathione Concentration in First Episode Psychosis: A 1H-MRS Investigation. Neurobiol. Dis. 2009, 33, 354-357, doi:10.1016/j.nbd.2008.11.018.

76. Berger, G.E.; Wood, S.J.; Wellard, R.M.; Proffitt, T.M.; McConchie, M.; Amminger, G.P.; Jackson, G.D.; Velakoulis, D.; Pantelis, C.; McGorry, P.D. Ethyl-Eicosapentaenoic Acid in First-Episode Psychosis. A 1H-MRS Study. Neuropsychopharmacol. Off. Publ. Am. Coll. Neuropsychopharmacol. 2008, 33, 2467-2473, doi:10.1038/sj.npp.1301628.

77. Jeon, P.; Limongi, R.; Ford, S.D.; Branco, C.; Mackinley, M.; Gupta, M.; Powe, L.; Théberge, J.; Palaniyappan, L. Glutathione as a Molecular Marker of Functional Impairment in Patients with At-Risk Mental State: 7-Tesla 1H-MRS Study. Brain Sci. 2021, 11, 941, doi:10.3390/brainsci11070941.

78. Yang, K.; Longo, L.; Narita, Z.; Cascella, N.; Nucifora, F.C.; Coughlin, J.M.; Nestadt, G.; Sedlak, T.W.; Mihaljevic, M.; Wang, M.; et al. A Multimodal Study of a First Episode Psychosis Cohort: Potential Markers of Antipsychotic Treatment Resistance. bioRxiv 2021, 2021.05.03.442450, doi:10.1101/2021.05.03.442450.

79. Kraguljac, N.V.; Morgan, C.J.; Reid, M.A.; White, D.M.; Jindal, R.D.; Sivaraman, S.; Martinak, B.K.; Lahti, A.C. A Longitudinal Magnetic Resonance Spectroscopy Study Investigating Effects of Risperidone in the Anterior Cingulate Cortex and Hippocampus in Schizophrenia. Schizophr. Res. 2019, 210, 239-244, doi:10.1016/j.schres.2018.12.028.

80. Merritt, K.; Perez-Iglesias, R.; Sendt, K.-V.; Goozee, R.; Jauhar, S.; Pepper, F.; Barker, G.J.; Glenthøj, B.; Arango, C.; Lewis, S.; et al. Remission from Antipsychotic Treatment in First Episode Psychosis Related to Longitudinal Changes in Brain Glutamate. Npj Schizophr. 2019, 5, 1-9, doi:10.1038/s41537-019-0080-1. 
81. Egerton, A.; Broberg, B.V.; Van Haren, N.; Merritt, K.; Barker, G.J.; Lythgoe, D.J.; Perez-Iglesias, R.; Baandrup, L.; Düring, S.W.; Sendt, K.V.; et al. Response to Initial Antipsychotic Treatment in First Episode Psychosis Is Related to Anterior Cingulate Glutamate Levels: A Multicentre 1H-MRS Study (OPTiMiSE). Mol. Psychiatry 2018, 23, 2145-2155, doi:10.1038/s41380-018-0082-9.

82. de la Fuente-Sandoval, C.; León-Ortiz, P.; Azcárraga, M.; Stephano, S.; Favila, R.; Díaz-Galvis, L.; Alvarado-Alanis, P.; Ramírez-Bermúdez, J.; Graff-Guerrero, A. Glutamate Levels in the Associative Striatum before and after 4 Weeks of Antipsychotic Treatment in First-Episode Psychosis: A Longitudinal Proton Magnetic Resonance Spectroscopy Study. JAMA Psychiatry 2013, 70, 1057-1066, doi:10.1001/jamapsychiatry.2013.289.

83. Théberge, J.; Williamson, K.E.; Aoyama, N.; Drost, D.J.; Manchanda, R.; Malla, A.K.; Northcott, S.; Menon, R.S.; Neufeld, R.W.J.; Rajakumar, N.; et al. Longitudinal Grey-Matter and Glutamatergic Losses in First-Episode Schizophrenia. Br. J. Psychiatry J. Ment. Sci. 2007, 191, 325-334, doi:10.1192/bjp.bp.106.033670.

84. Jeon, P.; Limongi, R.; Ford, S.D.; Mackinley, M.; Dempster, K.; Théberge, J.; Palaniyappan, L. Progressive Changes in Glutamate Concentration in Early Stages of Schizophrenia: A Longitudinal 7-Tesla MRS Study. Schizophr. Bull. Open 2021, 2, doi:10.1093/schizbullopen/sgaa072.

85. Wang, M.; Barker, P.B.; Cascella, N.; Coughlin, J.M.; Nestadt, G.; Nucifora, F.C.; Sedlak, T.W.; Kelly, A.; Younes, L.; Geman, D.; et al. Longitudinal Changes in Brain Metabolites in Healthy Subjects and Patients with First Episode Psychosis (FEP): A 7-Tesla MRS Study. bioRxiv 2020, 2020.08.25.267419, doi:10.1101/2020.08.25.267419.

86. Da Silva, T.; Hafizi, S.; Andreazza, A.C.; Kiang, M.; Bagby, R.M.; Navas, E.; Laksono, I.; Truong, P.; Gerritsen, C.; Prce, I.; et al. Glutathione, the Major Redox Regulator, in the Prefrontal Cortex of Individuals at Clinical High Risk for Psychosis. Int. J. Neuropsychopharmacol. 2018, 21, 311-318, doi:10.1093/ijnp/pyx094.

87. Zhang, Y.; Catts, V.S.; Shannon Weickert, C. Lower Antioxidant Capacity in the Prefrontal Cortex of Individuals with Schizophrenia. Aust. N. Z. J. Psychiatry 2017, 0004867417728805, doi:10.1177/0004867417728805.

88. Zhang, Y.; Catts, V.S.; Shannon Weickert, C. Lower Antioxidant Capacity in the Prefrontal Cortex of Individuals with Schizophrenia. Aust. N. Z. J. Psychiatry 2018, 52, 690-698, doi:10.1177/0004867417728805.

89. Ermakov, E.A.; Dmitrieva, E.M.; Parshukova, D.A.; Kazantseva, D.V.; Vasilieva, A.R.; Smirnova, L.P. Oxidative StressRelated Mechanisms in Schizophrenia Pathogenesis and New Treatment Perspectives. Oxid. Med. Cell. Longev. 2021, 2021, 8881770, doi:10.1155/2021/8881770.

90. Smigielski, L.; Jagannath, V.; Rössler, W.; Walitza, S.; Grünblatt, E. Epigenetic Mechanisms in Schizophrenia and Other Psychotic Disorders: A Systematic Review of Empirical Human Findings. Mol. Psychiatry 2020, 25, 1718-1748, doi:10.1038/s41380-019-0601-3.

91. Chitty, K.M.; Lagopoulos, J.; Hickie, I.B.; Hermens, D.F. The Impact of Alcohol and Tobacco Use on in Vivo Glutathione in Youth with Bipolar Disorder: An Exploratory Study. J. Psychiatr. Res. 2014, 55, 59-67, doi:10.1016/j.jpsychires.2014.03.024.

92. Tong, J.; Fitzmaurice, P.S.; Moszczynska, A.; Mattina, K.; Ang, L.-C.; Boileau, I.; Furukawa, Y.; Sailasuta, N.; Kish, S.J. Do Glutathione Levels Decline in Aging Human Brain? Free Radic. Biol. Med. 2016, 93, 110-117, doi:10.1016/j.freeradbiomed.2016.01.029.

93. Hermens, D.F.; Hatton, S.N.; Lee, R.S.C.; Naismith, S.L.; Duffy, S.L.; Paul Amminger, G.; Kaur, M.; Scott, E.M.; Lagopoulos, J.; Hickie, I.B. In Vivo Imaging of Oxidative Stress and Fronto-Limbic White Matter Integrity in Young Adults with Mood Disorders. Eur. Arch. Psychiatry Clin. Neurosci. 2018, 268, 145-156, doi:10.1007/s00406-017-0788-8.

94. Chitty, K.M.; Lagopoulos, J.; Hickie, I.B.; Hermens, D.F. A Longitudinal Proton Magnetic Resonance Spectroscopy Study Investigating Oxidative Stress as a Result of Alcohol and Tobacco Use in Youth with Bipolar Disorder. J. Affect. Disord. 2015, 175, 481-487, doi:10.1016/j.jad.2015.01.021.

95. Chitty, K.M.; Lagopoulos, J.; Hickie, I.B.; Hermens, D.F. Risky Alcohol Use in Young Persons with Emerging Bipolar Disorder Is Associated with Increased Oxidative Stress. J. Affect. Disord. 2013, 150, 1238-1241, doi:10.1016/j.jad.2013.06.003. 
96. Freed, R.D.; Hollenhorst, C.N.; Weiduschat, N.; Mao, X.; Kang, G.; Shungu, D.C.; Gabbay, V. A Pilot Study of Cortical Glutathione in Youth with Depression. Psychiatry Res. Neuroimaging 2017, 270, 54-60, doi:10.1016/j.pscychresns.2017.10.001.

97. Fisher, E.; Gillam, J.; Upthegrove, R.; Aldred, S.; Wood, S.J. Role of Magnetic Resonance Spectroscopy in Cerebral Glutathione Quantification for Youth Mental Health: A Systematic Review. Early Interv. Psychiatry 2020, 14, 147-162, doi:10.1111/eip.12833.

98. Draganov, M.; Vives-Gilabert, Y.; de Diego-Adeliño, J.; Vicent-Gil, M.; Puigdemont, D.; Portella, M.J. Glutamatergic and GABA-Ergic Abnormalities in First-Episode Depression. A 1-Year Follow-up 1H-MR Spectroscopic Study. J. Affect. Disord. 2020, 266, 572-577, doi:10.1016/j.jad.2020.01.138.

99. Duffy, S.L.; Lagopoulos, J.; Cockayne, N.; Hermens, D.F.; Hickie, I.B.; Naismith, S.L. Oxidative Stress and Depressive Symptoms in Older Adults: A Magnetic Resonance Spectroscopy Study. J. Affect. Disord. 2015, 180, 29-35, doi:10.1016/j.jad.2015.03.007.

100. Solberg, D.K.; Refsum, H.; Andreassen, O.A.; Bentsen, H. A Five-Year Follow-up Study of Antioxidants, Oxidative Stress and Polyunsaturated Fatty Acids in Schizophrenia. Acta Neuropsychiatr. 2019, 31, 202-212, doi:10.1017/neu.2019.14.

101. Ballesteros, A.; Jiang, P.; Summerfelt, A.; Du, X.; Chiappelli, J.; O’Donnell, P.; Kochunov, P.; Hong, L.E. No Evidence of Exogenous Origin for the Abnormal Glutathione Redox State in Schizophrenia. Schizophr. Res. 2013, 146, 184-189, doi:10.1016/j.schres.2013.02.001.

102. Lesh, T.A.; Maddock, R.J.; Howell, A.; Wang, H.; Tanase, C.; Daniel Ragland, J.; Niendam, T.A.; Carter, C.S. Extracellular Free Water and Glutathione in First-Episode Psychosis - a Multimodal Investigation of an Inflammatory Model for Psychosis. Mol. Psychiatry 2019, 1-11, doi:10.1038/s41380-019-0428-y.

103. Palaniyappan, L.; Al-Radaideh, A.; Mougin, O.; Gowland, P.; Liddle, P.F. Combined White Matter Imaging Suggests Myelination Defects in Visual Processing Regions in Schizophrenia. Neuropsychopharmacology 2013, 38, $1808-1815$.

104. Palaniyappan, L.; Das, T.; Dempster, K. The Neurobiology of Transition to Psychosis: Clearing the Cache. J. Psychiatry Neurosci. 2017, 42, 294-299.

105. Cassoli, J.S.; Guest, P.C.; Malchow, B.; Schmitt, A.; Falkai, P.; Martins-de-Souza, D. Disturbed Macro-Connectivity in Schizophrenia Linked to Oligodendrocyte Dysfunction: From Structural Findings to Molecules. NPJ Schizophr. 2015, 1, 15034, doi:10.1038/npjschz.2015.34.

106. Voineskos, A.N.; Felsky, D.; Kovacevic, N.; Tiwari, A.K.; Zai, C.; Chakravarty, M.M.; Lobaugh, N.J.; Shenton, M.E.; Rajji, T.K.; Miranda, D.; et al. Oligodendrocyte Genes, White Matter Tract Integrity, and Cognition in Schizophrenia. Cereb. Cortex N. Y. N 1991 2012, doi:10.1093/cercor/bhs188.

107. French, H.M.; Reid, M.; Mamontov, P.; Simmons, R.A.; Grinspan, J.B. Oxidative Stress Disrupts Oligodendrocyte Maturation. J. Neurosci. Res. 2009, 87, 3076-3087, doi:10.1002/jnr.22139.

108. Uranova, N.A.; Vikhreva, O.V.; Rakhmanova, V.I.; Orlovskaya, D.D. Dystrophy of Oligodendrocytes and Adjacent Microglia in Prefrontal Gray Matter in Schizophrenia. Front. Psychiatry 2020, 11, doi:10.3389/fpsyt.2020.00204.

109. Mauney, S.A.; Pietersen, C.Y.; Sonntag, K.-C.; Woo, T.-U.W. Differentiation of Oligodendrocyte Precursors Is Impaired in the Prefrontal Cortex in Schizophrenia. Schizophr. Res. 2015, 169, 374-380, doi:10.1016/j.schres.2015.10.042.

110. Stedehouder, J.; Kushner, S.A. Myelination of Parvalbumin Interneurons: A Parsimonious Locus of Pathophysiological Convergence in Schizophrenia. Mol. Psychiatry 2017, 22, 4-12, doi:10.1038/mp.2016.147.

111. Palaniyappan, L. Inefficient Neural System Stabilization: A Theory of Spontaneous Resolutions and Recurrent Relapses in Psychosis. J. Psychiatry Neurosci. JPN 2019, 44, 1-17, doi:10.1503/jpn.180038.

112. Dietsche, B.; Kircher, T.; Falkenberg, I. Structural Brain Changes in Schizophrenia at Different Stages of the Illness: A Selective Review of Longitudinal Magnetic Resonance Imaging Studies. Aust. N. Z. J. Psychiatry 2017, 51, 500-508, doi:10.1177/0004867417699473. 
113. Lu, P.H.; Lee, G.J.; Raven, E.P.; Tingus, K.; Khoo, T.; Thompson, P.M.; Bartzokis, G. Age-Related Slowing in Cognitive Processing Speed Is Associated with Myelin Integrity in a Very Healthy Elderly Sample. J. Clin. Exp. Neuropsychol. 2011, 33, 1059-1068, doi:10.1080/13803395.2011.595397.

114. Croteau-Chonka, E.C.; Dean III, D.C.; Remer, J.; Dirks, H.; O’Muircheartaigh, J.; Deoni, S.C.L. Examining the Relationships between Cortical Maturation and White Matter Myelination throughout Early Childhood. NeuroImage 2016, 125, 413-421, doi:10.1016/j.neuroimage.2015.10.038.

115. Whitaker, K.J.; Vértes, P.E.; Romero-Garcia, R.; Váša, F.; Moutoussis, M.; Prabhu, G.; Weiskopf, N.; Callaghan, M.F.; Wagstyl, K.; Rittman, T.; et al. Adolescence Is Associated with Genomically Patterned Consolidation of the Hubs of the Human Brain Connectome. Proc. Natl. Acad. Sci. 2016, 201601745, doi:10.1073/pnas.1601745113.

116. Micheva, K.D.; Wolman, D.; Mensh, B.D.; Pax, E.; Buchanan, J.; Smith, S.J.; Bock, D.D. A Large Fraction of Neocortical Myelin Ensheathes Axons of Local Inhibitory Neurons. eLife 2016, 5, e15784, doi:10.7554/eLife.15784.

117. Lewis, D.A.; Curley, A.A.; Glausier, J.R.; Volk, D.W. Cortical Parvalbumin Interneurons and Cognitive Dysfunction in Schizophrenia. Trends Neurosci. 2012, 35, 57-67, doi:10.1016/j.tins.2011.10.004.

118. Stedehouder, J.; Kushner, S.A. Myelination of Parvalbumin Interneurons: A Parsimonious Locus of Pathophysiological Convergence in Schizophrenia. Mol. Psychiatry 2016, doi:10.1038/mp.2016.147.

119. Lambert, M.; Naber, D.; Schacht, A.; Wagner, T.; Hundemer, H.-P.; Karow, A.; Huber, C.G.; Suarez, D.; Haro, J.M.; Novick, D.; et al. Rates and Predictors of Remission and Recovery during 3 Years in 392 Never-Treated Patients with Schizophrenia. Acta Psychiatr. Scand. 2008, 118, 220-229, doi:10.1111/j.1600-0447.2008.01213.x.

120. Derks, E.M.; Fleischhacker, W.W.; Boter, H.; Peuskens, J.; Kahn, R.S.; EUFEST Study Group Antipsychotic Drug Treatment in First-Episode Psychosis: Should Patients Be Switched to a Different Antipsychotic Drug after 2, 4, or 6 Weeks of Nonresponse? J. Clin. Psychopharmacol. 2010, 30, 176-180, doi:10.1097/JCP.0b013e3181d2193c.

121. Carbon, M.; Correll, C.U. Clinical Predictors of Therapeutic Response to Antipsychotics in Schizophrenia. Dialogues Clin. Neurosci. 2014, 16, 505-524.

122. Matsuzawa, D.; Obata, T.; Shirayama, Y.; Nonaka, H.; Kanazawa, Y.; Yoshitome, E.; Takanashi, J.; Matsuda, T.; Shimizu, E.; Ikehira, H.; et al. Negative Correlation between Brain Glutathione Level and Negative Symptoms in Schizophrenia: A $3 \mathrm{~T}$ 1HMRS Study: E1944. PLoS One 2008, 3, doi:http://dx.doi.org.proxy1.lib.uwo.ca/10.1371/journal.pone.0001944.

123. Sedlak, T.W.; Paul, B.D.; Parker, G.M.; Hester, L.D.; Snowman, A.M.; Taniguchi, Y.; Kamiya, A.; Snyder, S.H.; Sawa, A. The Glutathione Cycle Shapes Synaptic Glutamate Activity. Proc. Natl. Acad. Sci. 2019, 201817885, doi:10.1073/pnas.1817885116.

124. Koga, M.; Serritella, A.V.; Messmer, M.M.; Hayashi-Takagi, A.; Hester, L.D.; Snyder, S.H.; Sawa, A.; Sedlak, T.W. Glutathione Is a Physiologic Reservoir of Neuronal Glutamate. Biochem. Biophys. Res. Commun. 2011, 409, 596-602, doi:10.1016/j.bbrc.2011.04.087.

125. Egerton, A.; Brugger, S.; Raffin, M.; Barker, G.J.; Lythgoe, D.J.; McGuire, P.K.; Stone, J.M. Anterior Cingulate Glutamate Levels Related to Clinical Status Following Treatment in First-Episode Schizophrenia. Neuropsychopharmacology 2012, 37, 2515-2521, doi:10.1038/npp.2012.113.

126. Shah, P.; Plitman, E.; Iwata, Y.; Kim, J.; Nakajima, S.; Chan, N.; Brown, E.E.; Caravaggio, F.; Torres, E.; Hahn, M.; et al. Glutamatergic Neurometabolites and Cortical Thickness in Treatment-Resistant Schizophrenia: Implications for GlutamateMediated Excitotoxicity. J. Psychiatr. Res. 2020, 124, 151-158, doi:10.1016/j.jpsychires.2020.02.032.

127. Plitman, E.; Nakajima, S.; de la Fuente-Sandoval, C.; Gerretsen, P.; Chakravarty, M.M.; Kobylianskii, J.; Chung, J.K.; Caravaggio, F.; Iwata, Y.; Remington, G.; et al. Glutamate-Mediated Excitotoxicity in Schizophrenia: A Review. Eur. Neuropsychopharmacol. J. Eur. Coll. Neuropsychopharmacol. 2014, 24, 1591-1605, doi:10.1016/j.euroneuro.2014.07.015.

128. Langbein, K.; Hesse, J.; Gussew, A.; Milleit, B.; Lavoie, S.; Amminger, G.P.; Gaser, C.; Wagner, G.; Reichenbach, J.R.; Hipler, U.-C.; et al. Disturbed Glutathione Antioxidative Defense Is Associated with Structural Brain Changes in Neuroleptic-Naïve First-Episode Psychosis Patients. Prostaglandins Leukot. Essent. Fatty Acids 2018, 136, 103-110, doi:10.1016/j.plefa.2017.10.005. 
129. Fraguas, D.; Gonzalez-Pinto, A.; Micó, J.A.; Reig, S.; Parellada, M.; Martínez-Cengotitabengoa, M.; Castro-Fornieles, J.; Rapado-Castro, M.; Baeza, I.; Janssen, J.; et al. Decreased Glutathione Levels Predict Loss of Brain Volume in Children and Adolescents with First-Episode Psychosis in a Two-Year Longitudinal Study. Schizophr. Res. 2012, 137, 58-65, doi:10.1016/j.schres.2012.01.040.

130. Merritt, K.; McGuire, P.K.; Egerton, A.; 1H-MRS in Schizophrenia Investigators; Aleman, A.; Block, W.; Bloemen, O.J.N.; Borgan, F.; Bustillo, J.R.; Capizzano, A.A.; et al. Association of Age, Antipsychotic Medication, and Symptom Severity in Schizophrenia With Proton Magnetic Resonance Spectroscopy Brain Glutamate Level: A Mega-Analysis of Individual Participant-Level Data. JAMA Psychiatry 2021, doi:10.1001/jamapsychiatry.2021.0380.

131. Smucny, J.; Carter, C.S.; Maddock, R.J. Medial Prefrontal Cortex Glutamate Is Reduced in Schizophrenia and Moderated by Measurement Quality: A Meta-Analysis of Proton Magnetic Resonance Spectroscopy Studies. Biol. Psychiatry 2021, S00063223(21)01393-7, doi:10.1016/j.biopsych.2021.06.008.

132. Martínez-Maestro, M.; Labadie, C.; Möller, H.E. Dynamic Metabolic Changes in Human Visual Cortex in Regions with Positive and Negative Blood Oxygenation Level-Dependent Response. J. Cereb. Blood Flow Metab. Off. J. Int. Soc. Cereb. Blood Flow Metab. 2019, 39, 2295-2307, doi:10.1177/0271678X18795426.

133. Jeon, P. Functional Magnetic Resonance Spectroscopy in First-Episode Schizophrenia: Measuring Glutamate and Glutathione Dynamics at 7-Tesla. Electron. Thesis Diss. Repos. 2019.

134. Lin, Y.; Stephenson, M.C.; Xin, L.; Napolitano, A.; Morris, P.G. Investigating the Metabolic Changes Due to Visual Stimulation Using Functional Proton Magnetic Resonance Spectroscopy at 7 T. J. Cereb. Blood Flow Metab. Off. J. Int. Soc. Cereb. Blood Flow Metab. 2012, 32, 1484-1495, doi:10.1038/jcbfm.2012.33.

135. Boillat, Y.; Xin, L.; van der Zwaag, W.; Gruetter, R. Metabolite Concentration Changes Associated with Positive and Negative BOLD Responses in the Human Visual Cortex: A Functional MRS Study at 7 Tesla. J. Cereb. Blood Flow Metab. Off. J. Int. Soc. Cereb. Blood Flow Metab. 2020, 40, 488-500, doi:10.1177/0271678X19831022.

136. Schaller, B.; Xin, L.; O’Brien, K.; Magill, A.W.; Gruetter, R. Are Glutamate and Lactate Increases Ubiquitous to Physiological Activation? A (1)H Functional MR Spectroscopy Study during Motor Activation in Human Brain at 7Tesla. Neurolmage 2014, 93 Pt 1, 138-145, doi:10.1016/j.neuroimage.2014.02.016.

137. Bednařík, P.; Tkáč, I.; Giove, F.; DiNuzzo, M.; Deelchand, D.K.; Emir, U.E.; Eberly, L.E.; Mangia, S. Neurochemical and BOLD Responses during Neuronal Activation Measured in the Human Visual Cortex at 7 Tesla. J. Cereb. Blood Flow Metab. Off. J. Int. Soc. Cereb. Blood Flow Metab. 2015, 35, 601-610, doi:10.1038/jcbfm.2014.233.

138. Justin, A.; Sathishkumar, M.; Sudheer, A.; Shanthakumari, S.; Ramanathan, M. Non-Hypotensive Dose of Telmisartan and Nimodipine Produced Synergistic Neuroprotective Effect in Cerebral Ischemic Model by Attenuating Brain Cytokine Levels. Pharmacol. Biochem. Behav. 2014, 122, 61-73, doi:10.1016/j.pbb.2014.03.009.

139. Liang, M.; Wang, Z.; Li, H.; Cai, L.; Pan, J.; He, H.; Wu, Q.; Tang, Y.; Ma, J.; Yang, L. L-Arginine Induces Antioxidant Response to Prevent Oxidative Stress via Stimulation of Glutathione Synthesis and Activation of Nrf2 Pathway. Food Chem. Toxicol. 2018, 115, 315-328, doi:10.1016/j.fct.2018.03.029.

140. Verma, M.K.; Goel, R.; Nandakumar, K.; Nemmani, K.V.S. Effect of D-Ala2GIP, a Stable GIP Receptor Agonist on MPTPInduced Neuronal Impairments in Mice. Eur. J. Pharmacol. 2017, 804, 38-45, doi:10.1016/j.ejphar.2017.03.059.

141. Bramanti, V.; Tomassoni, D.; Bronzi, D.; Grasso, S.; Currò, M.; Avitabile, M.; Li Volsi, G.; Renis, M.; Ientile, R.; Amenta, F.; et al. Alpha-Lipoic Acid Modulates GFAP, Vimentin, Nestin, Cyclin D1 and MAP-Kinase Espression in Astroglial Cell Cultures. Neurochem. Res. 2010, 35, 2070-2077, doi:10.1007/s11064-010-0256-6.

142. Pawełczyk, T.; Grancow, M.; Kotlicka-Antczak, M.; Trafalska, E.; Gębski, P.; Szemraj, J.; Żurner, N.; Pawełczyk, A. Omega-3 Fatty Acids in First-Episode Schizophrenia - a Randomized Controlled Study of Efficacy and Relapse Prevention (OFFER): Rationale, Design, and Methods. BMC Psychiatry 2015, 15, doi:10.1186/s12888-015-0473-2. 
143. Nakamura, Y.; Feng, Q.; Kumagai, T.; Torikai, K.; Ohigashi, H.; Osawa, T.; Noguchi, N.; Niki, E.; Uchida, K. Ebselen, a Glutathione Peroxidase Mimetic Seleno-Organic Compound, as a Multifunctional Antioxidant. Implication for Inflammation-Associated Carcinogenesis. J. Biol. Chem. 2002, 277, 2687-2694, doi:10.1074/jbc.M109641200.

144. Maugard, M.; Vigneron, P.-A.; Bolaños, J.P.; Bonvento, G. L-Serine Links Metabolism with Neurotransmission. Prog. Neurobiol. 2020, 101896, doi:10.1016/j.pneurobio.2020.101896.

145. Fujita, Y.; Ishima, T.; Hashimoto, K. Supplementation with D-Serine Prevents the Onset of Cognitive Deficits in Adult Offspring after Maternal Immune Activation. Sci. Rep. 2016, 6, 37261, doi:10.1038/srep37261.

146. Tchantchou, F.; Graves, M.; Falcone, D.; Shea, T.B. S-Adenosylmethionine Mediates Glutathione Efficacy by Increasing Glutathione S-Transferase Activity: Implications for S-Adenosyl Methionine as a Neuroprotective Dietary Supplement. J. Alzheimers Dis. JAD 2008, 14, 323-328, doi:10.3233/jad-2008-14306.

147. Sharma, A.; Gerbarg, P.; Bottiglieri, T.; Massoumi, L.; Carpenter, L.L.; Lavretsky, H.; Muskin, P.R.; Brown, R.P.; Mischoulon, D. S-Adenosylmethionine (SAMe) for Neuropsychiatric Disorders: A Clinician-Oriented Review of Research. J. Clin. Psychiatry 2017, 78, e656-e667, doi:10.4088/JCP.16r11113.

148. Sekhar, R.V.; McKay, S.V.; Patel, S.G.; Guthikonda, A.P.; Reddy, V.T.; Balasubramanyam, A.; Jahoor, F. Glutathione Synthesis Is Diminished in Patients With Uncontrolled Diabetes and Restored by Dietary Supplementation With Cysteine and Glycine. Diabetes Care 2011, 34, 162-167, doi:10.2337/dc10-1006.

149. Albrecht, P.; Bouchachia, I.; Goebels, N.; Henke, N.; Hofstetter, H.H.; Issberner, A.; Kovacs, Z.; Lewerenz, J.; Lisak, D.; Maher, P.; et al. Effects of Dimethyl Fumarate on Neuroprotection and Immunomodulation. J. Neuroinflammation 2012, 9, 163, doi:10.1186/1742-2094-9-163.

150. Abd El-Fattah, A.A.; Fahim, A.T.; Sadik, N.A.H.; Ali, B.M. Resveratrol and Dimethyl Fumarate Ameliorate Depression-like Behaviour in a Rat Model of Chronic Unpredictable Mild Stress. Brain Res. 2018, 1701, 227-236, doi:10.1016/j.brainres.2018.09.027.

151. Lavoie, S.; Chen, Y.; Dalton, T.P.; Gysin, R.; Cuénod, M.; Steullet, P.; Do, K.Q. Curcumin, Quercetin, and TBHQ Modulate Glutathione Levels in Astrocytes and Neurons: Importance of the Glutamate Cysteine Ligase Modifier Subunit. J. Neurochem. 2009, 108, 1410-1422, doi:10.1111/j.1471-4159.2009.05908.x.

152. Miodownik, C.; Lerner, V.; Kudkaeva, N.; Lerner, P.P.; Pashinian, A.; Bersudsky, Y.; Eliyahu, R.; Kreinin, A.; Bergman, J. Curcumin as Add-On to Antipsychotic Treatment in Patients With Chronic Schizophrenia: A Randomized, Double-Blind, Placebo-Controlled Study. Clin. Neuropharmacol. 2019, 42, 117-122, doi:10.1097/WNF.0000000000000344.

153. Rodríguez-Navarro, J.A.; Rodríguez, L.; Casarejos, M.J.; Solano, R.M.; Gómez, A.; Perucho, J.; Cuervo, A.M.; García de Yébenes, J.; Mena, M.A. Trehalose Ameliorates Dopaminergic and Tau Pathology in Parkin Deleted/Tau Overexpressing Mice through Autophagy Activation. Neurobiol. Dis. 2010, 39, 423-438, doi:10.1016/j.nbd.2010.05.014.

154. Sinha, R.; Sinha, I.; Calcagnotto, A.; Trushin, N.; Haley, J.S.; Schell, T.D.; Richie, J.P. Oral Supplementation with Liposomal Glutathione Elevates Body Stores of Glutathione and Markers of Immune Function. Eur. J. Clin. Nutr. 2018, 72, 105-111, doi:10.1038/ejcn.2017.132.

155. Zortea, K.; Franco, V.C.; Guimarães, P.; Belmonte-de-Abreu, P.S. Resveratrol Supplementation Did Not Improve Cognition in Patients with Schizophrenia: Results from a Randomized Clinical Trial. Front. Psychiatry 2016, 7, doi:10.3389/fpsyt.2016.00159.

156. Kode, A.; Rajendrasozhan, S.; Caito, S.; Yang, S.-R.; Megson, I.L.; Rahman, I. Resveratrol Induces Glutathione Synthesis by Activation of Nrf2 and Protects against Cigarette Smoke-Mediated Oxidative Stress in Human Lung Epithelial Cells. Am. J. Physiol. Lung Cell. Mol. Physiol. 2008, 294, L478-488, doi:10.1152/ajplung.00361.2007.

157. Mert, D.G.; Turgut, N.H.; Arslanbas, E.; Gungor, H.; Kara, H. The Influence of Quercetin on Recognition Memory and Brain Oxidative Damage in a Ketamine Model of Schizophrenia. Psychiatry Clin. Psychopharmacol. 2019, 29, 1-7, doi:10.1080/24750573.2018.1442670. 
158. Schwartz, D.L. Quercetin as an Augmentation Agent in Schizophrenia. J. Clin. Psychopharmacol. 2016, 36, 282-283, doi:10.1097/JCP.0000000000000498.

159. Suresh, P.; Raju, A.B. Antidopaminergic Effects of Leucine and Genistein on Shizophrenic Rat Models. Neurosci. Riyadh Saudi Arab. 2013, 18, 235-241.

160. Torrens-Mas, M.; Pons, D.-G.; Sastre-Serra, J.; Oliver, J.; Roca, P. Sexual Hormones Regulate the Redox Status and Mitochondrial Function in the Brain. Pathological Implications. Redox Biol. 2020, 31, 101505, doi:10.1016/j.redox.2020.101505.

161. Mussard, E.; Cesaro, A.; Lespessailles, E.; Legrain, B.; Berteina-Raboin, S.; Toumi, H. Andrographolide, A Natural Antioxidant: An Update. Antioxidants 2019, 8, doi:10.3390/antiox8120571.

162. Schopfer, F.J.; Vitturi, D.A.; Jorkasky, D.K.; Freeman, B.A. Nitro-Fatty Acids: New Drug Candidates for Chronic Inflammatory and Fibrotic Diseases. Nitric Oxide Biol. Chem. 2018, 79, 31-37, doi:10.1016/j.niox.2018.06.006.

163. Lynch, D.R.; Farmer, J.; Hauser, L.; Blair, I.A.; Wang, Q.Q.; Mesaros, C.; Snyder, N.; Boesch, S.; Chin, M.; Delatycki, M.B.; et al. Safety, Pharmacodynamics, and Potential Benefit of Omaveloxolone in Friedreich Ataxia. Ann. Clin. Transl. Neurol. 2019, 6, 15-26, doi:10.1002/acn3.660.

164. Pinto, M.C.X.; Mourão, F.A.G.; Binda, N.S.; Leite, H.R.; Gomez, M.V.; Massensini, A.R.; Gomez, R.S. Pharmacological Induction of Ischemic Tolerance in Hippocampal Slices by Sarcosine Preconditioning. Neurochem. Int. 2012, 61, 713-720, doi:10.1016/j.neuint.2012.06.018.

165. Curtis, D. A Possible Role for Sarcosine in the Management of Schizophrenia. Br. J. Psychiatry 2019, 215, 697-698, doi:10.1192/bjp.2019.194.

166. Tsilioni, I.; Taliou, A.; Francis, K.; Theoharides, T.C. Children with Autism Spectrum Disorders, Who Improved with a Luteolin-Containing Dietary Formulation, Show Reduced Serum Levels of TNF and IL-6. Transl. Psychiatry 2015, 5, e647e647, doi:10.1038/tp.2015.142.

167. Pereira, R.B.; Sousa, C.; Costa, A.; Andrade, P.B.; Valentão, P. Glutathione and the Antioxidant Potential of Binary Mixtures with Flavonoids: Synergisms and Antagonisms. Molecules 2013, 18, 8858-8872, doi:10.3390/molecules18088858.

168. Yagishita, Y.; Gatbonton-Schwager, T.N.; McCallum, M.L.; Kensler, T.W. Current Landscape of NRF2 Biomarkers in Clinical Trials. Antioxidants 2020, 9, 716, doi:10.3390/antiox9080716.

169. Yolland, C.O.; Hanratty, D.; Neill, E.; Rossell, S.L.; Berk, M.; Dean, O.M.; Castle, D.J.; Tan, E.J.; Phillipou, A.; Harris, A.W.; et al. Meta-Analysis of Randomised Controlled Trials with N-Acetylcysteine in the Treatment of Schizophrenia. Aust. N. Z. J. Psychiatry 2019, 4867419893439, doi:10.1177/0004867419893439.

170. Conus, P.; Seidman, L.J.; Fournier, M.; Xin, L.; Cleusix, M.; Baumann, P.S.; Ferrari, C.; Cousins, A.; Alameda, L.; GholamRezaee, M.; et al. N-Acetylcysteine in a Double-Blind Randomized Placebo-Controlled Trial: Toward Biomarker-Guided Treatment in Early Psychosis. Schizophr. Bull. 2018, 44, 317-327, doi:10.1093/schbul/sbx093.

171. Berk, M.; Malhi, G.S.; Gray, L.J.; Dean, O.M. The Promise of N-Acetylcysteine in Neuropsychiatry. Trends Pharmacol. Sci. 2013, 34, 167-177, doi:10.1016/j.tips.2013.01.001.

172. Robledinos-Antón, N.; Fernández-Ginés, R.; Manda, G.; Cuadrado, A. Activators and Inhibitors of NRF2: A Review of Their Potential for Clinical Development. Oxid. Med. Cell. Longev. 2019, 2019, e9372182, doi:https://doi.org/10.1155/2019/9372182.

173. Girgis, R.R.; Baker, S.; Mao, X.; Gil, R.; Javitt, D.C.; Kantrowitz, J.T.; Gu, M.; Spielman, D.M.; Ojeil, N.; Xu, X.; et al. Effects of Acute N-Acetylcysteine Challenge on Cortical Glutathione and Glutamate in Schizophrenia: A Pilot in Vivo Proton Magnetic Resonance Spectroscopy Study. Psychiatry Res. 2019, 275, 78-85, doi:10.1016/j.psychres.2019.03.018.

174. Kubo, E.; Chhunchha, B.; Singh, P.; Sasaki, H.; Singh, D.P. Sulforaphane Reactivates Cellular Antioxidant Defense by Inducing Nrf2/ARE/Prdx6 Activity during Aging and Oxidative Stress. Sci. Rep. 2017, 7, 14130, doi:10.1038/s41598-017-145208 .

175. Vomund, S.; Schäfer, A.; Parnham, M.J.; Brüne, B.; von Knethen, A. Nrf2, the Master Regulator of Anti-Oxidative Responses. Int. J. Mol. Sci. 2017, 18, doi:10.3390/ijms18122772. 
176. Fahey, J.W.; Holtzclaw, W.D.; Wehage, S.L.; Wade, K.L.; Stephenson, K.K.; Talalay, P. Sulforaphane Bioavailability from Glucoraphanin-Rich Broccoli: Control by Active Endogenous Myrosinase. PLOS ONE 2015, 10, e0140963, doi:10.1371/journal.pone.0140963.

177. Egner, P.A.; Chen, J.G.; Wang, J.B.; Wu, Y.; Sun, Y.; Lu, J.H.; Zhu, J.; Zhang, Y.H.; Chen, Y.S.; Friesen, M.D.; et al. Bioavailability of Sulforaphane from Two Broccoli Sprout Beverages: Results of a Short Term, Cross-over Clinical Trial in Qidong, China. Cancer Prev. Res. Phila. Pa 2011, 4, 384-395, doi:10.1158/1940-6207.CAPR-10-0296.

178. Sedlak, T.W.; Nucifora, L.G.; Koga, M.; Shaffer, L.S.; Higgs, C.; Tanaka, T.; Wang, A.M.; Coughlin, J.M.; Barker, P.B.; Fahey, J.W.; et al. Sulforaphane Augments Glutathione and Influences Brain Metabolites in Human Subjects: A Clinical Pilot Study. Mol. Neuropsychiatry 2018, 3, 214-222, doi:10.1159/000487639.

179. Houghton, C.A. Sulforaphane: Its "Coming of Age" as a Clinically Relevant Nutraceutical in the Prevention and Treatment of Chronic Disease Available online: https://www.hindawi.com/journals/omcl/2019/2716870/ (accessed on 26 September 2020).

180. Singh, K.; Connors, S.L.; Macklin, E.A.; Smith, K.D.; Fahey, J.W.; Talalay, P.; Zimmerman, A.W. Sulforaphane Treatment of Autism Spectrum Disorder (ASD). Proc. Natl. Acad. Sci. U. S. A. 2014, 111, 15550-15555, doi:10.1073/pnas.1416940111.

181. Shiina, A.; Kanahara, N.; Sasaki, T.; Oda, Y.; Hashimoto, T.; Hasegawa, T.; Yoshida, T.; Iyo, M.; Hashimoto, K. An Open Study of Sulforaphane-Rich Broccoli Sprout Extract in Patients with Schizophrenia. Clin. Psychopharmacol. Neurosci. 2015, 13, 62-67, doi:10.9758/cpn.2015.13.1.62.

182. Bent, S.; Lawton, B.; Warren, T.; Widjaja, F.; Dang, K.; Fahey, J.W.; Cornblatt, B.; Kinchen, J.M.; Delucchi, K.; Hendren, R.L. Identification of Urinary Metabolites That Correlate with Clinical Improvements in Children with Autism Treated with Sulforaphane from Broccoli. Mol. Autism 2018, 9, 35, doi:10.1186/s13229-018-0218-4.

183. Reid, M.A.; Salibi, N.; White, D.M.; Gawne, T.J.; Denney, T.S.; Lahti, A.C. 7T Proton Magnetic Resonance Spectroscopy of the Anterior Cingulate Cortex in First-Episode Schizophrenia. Schizophr. Bull. 2018, doi:10.1093/schbul/sbx190.

184. Hermens, D.F.; Lagopoulos, J.; Naismith, S.L.; Tobias-Webb, J.; Hickie, I.B. Distinct Neurometabolic Profiles Are Evident in the Anterior Cingulate of Young People with Major Psychiatric Disorders. Transl. Psychiatry 2012, 2, e110, doi:10.1038/tp.2012.35.

185. Bottino, F.; Lucignani, M.; Napolitano, A.; Dellepiane, F.; Visconti, E.; Rossi Espagnet, M.C.; Pasquini, L. In Vivo Brain GSH: MRS Methods and Clinical Applications. Antioxidants 2021, 10, 1407, doi:10.3390/antiox10091407.

186. Yamamoto, K.; Opina, A.; Sail, D.; Blackman, B.; Saito, K.; Brender, J.R.; Malinowski, R.M.; Seki, T.; Oshima, N.; Crooks, D.R.; et al. Real-Time Insight into in Vivo Redox Status Utilizing Hyperpolarized [1-13C] N-Acetyl Cysteine. Sci. Rep. 2021, 11, 12155, doi:10.1038/s41598-021-90921-0.

187. Chen, J.; Yadav, N.N.; Stait-Gardner, T.; Gupta, A.; Price, W.S.; Zheng, G. Thiol-Water Proton Exchange of Glutathione, Cysteine, and N-Acetylcysteine: Implications for CEST MRI. NMR Biomed. 2020, 33, e4188, doi:10.1002/nbm.4188.

188. Juchnowicz, D.; Dzikowski, M.; Rog, J.; Waszkiewicz, N.; Karakuła, K.H.; Zalewska, A.; Maciejczyk, M.; Karakula-Juchnowicz, H. Pro/Antioxidant State as a Potential Biomarker of Schizophrenia. J. Clin. Med. 2021, 10, 4156, doi:10.3390/jcm10184156.

189. Fournier, M.; Scolamiero, M.; Gholam-Rezaee, M.M.; Cleusix, M.; Jenni, R.; Ferrari, C.; Golay, P.; Baumann, P.S.; Cuenod, M.; Conus, P.; et al. Topology Predicts Long-Term Functional Outcome in Early Psychosis. Mol. Psychiatry 2020, 1-12, doi:10.1038/s41380-020-0826-1. 